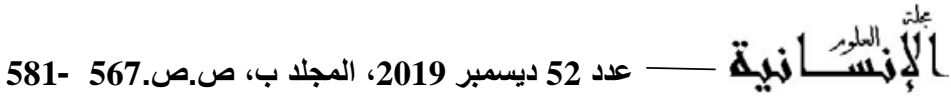

\title{
الدور الاقتصادي الجديد للجماعات المحلية في ظل أزمة التمويل
}

The new economic role of local communities in light of the funding crisis

تاريخ الاستلام : 2019/11/19 ؛ تاريخ القبول : 2019/12/01

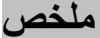

\begin{tabular}{|c|c|c|}
\hline 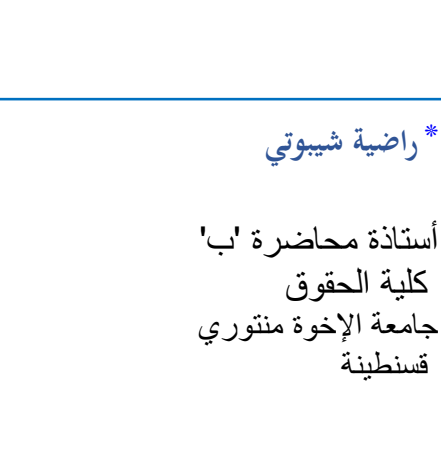 & \multicolumn{2}{|c|}{ 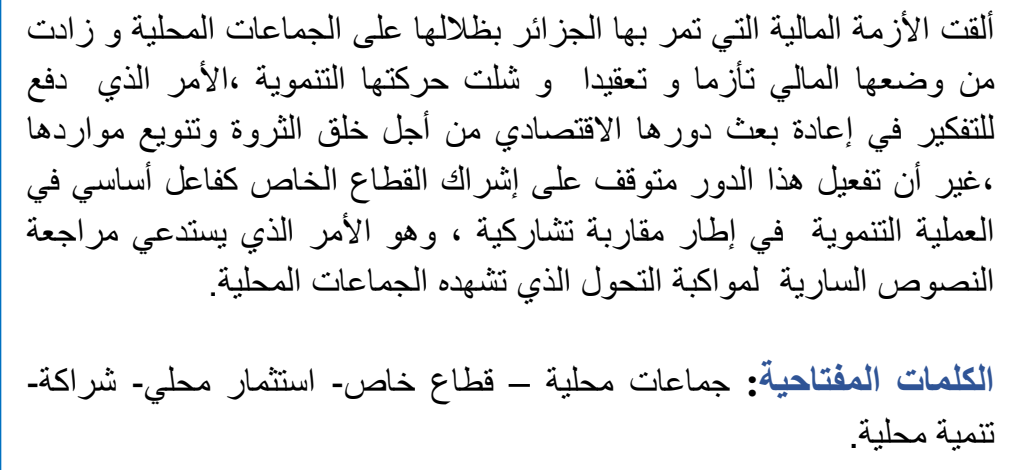 } \\
\hline \multicolumn{2}{|c|}{$\begin{array}{l}\text { Abstract } \\
\text { The financial crisis that Algeria is going through } \\
\text { has cast a shadow on the local communities, has } \\
\text { made its financial situation become increasingly } \\
\text { complex and has paralyzed its development } \\
\text { movement, This has led to the thought of } \\
\text { resurrecting its economic role to create wealth } \\
\text { and diversify its resources, however, the } \\
\text { realization of this role depends on the } \\
\text { involvement of the private sector as a key player } \\
\text { in the development process within a participatory } \\
\text { approach, which requires reviewing the texts and } \\
\text { regulations in force to cope with the } \\
\text { transformation witnessed by local communities. }\end{array}$} & $\begin{array}{l}\text { Résumé } \\
\text { L'Algérie passe par une crise financière qui a } \\
\text { touchée les collectivités locales, a rendu sa } \\
\text { situation financière plus critique et compliquée, et } \\
\text { paralysé son mouvement de développement, ce qui } \\
\text { a conduit à envisager la reprise de son rôle } \\
\text { économique afin de créer un récit et de diversifier } \\
\text { ses ressources, mais l'activation de ce rôle dépend } \\
\text { de l'implication du secteur privé en tant qu'acteur } \\
\text { clé du processus de développement dans le cadre } \\
\text { d'une approche participative, chose qui nécessite la } \\
\text { révision des textes en vigueur pour suivre le } \\
\text { rythme de la transformation des collectivités } \\
\text { locales. }\end{array}$ \\
\hline \multicolumn{2}{|c|}{$\begin{array}{l}\text { Keywords: Local Communities - Private Sector } \\
- \text { Local Investment - Partnership - Local } \\
\text { Development. }\end{array}$} & $\begin{array}{l}\text { Mots clés: Collectivités locales - secteur privé - } \\
\text { investissement local - partenariat - développement } \\
\text { local }\end{array}$ \\
\hline
\end{tabular}

* Corresponding author, e-mail: droit.radia@gmail.com 
ترتبط الجماعات المحلية بالدولة ارتباطا متعدد المستويات :سياسي ،إداري، و وإئ

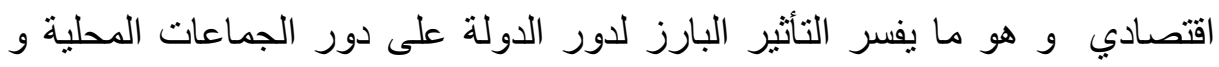
مكانتها، وتغيره بتغير الإيديولوجيات و هالئ التوجهات.

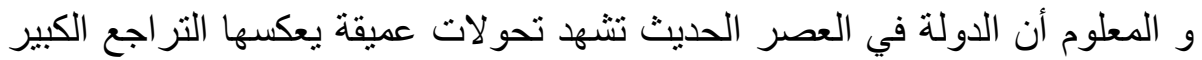

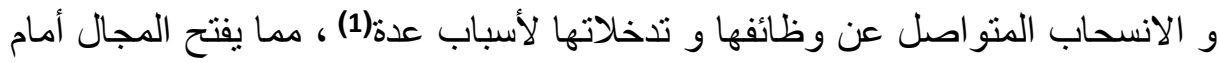

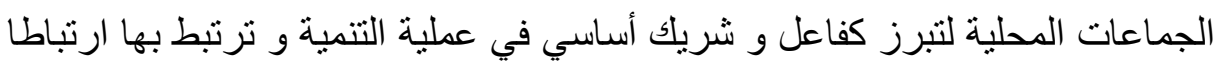

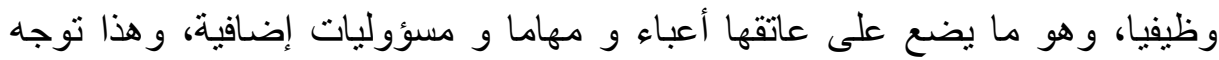
عالمي ذو بعد اقتصادي عرفته عديد الدول و دعت إعت إليه منظمات و ومؤسسات مالية

دولية عديدة.

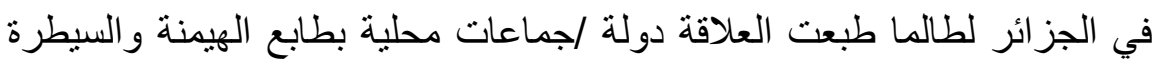

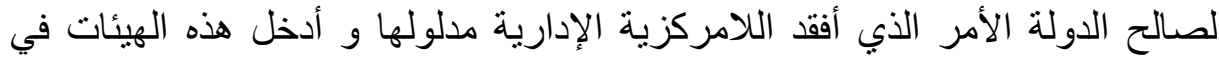

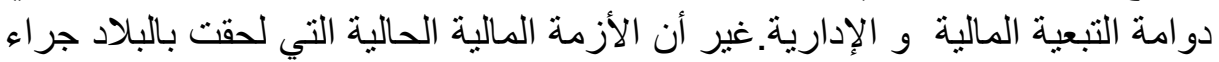

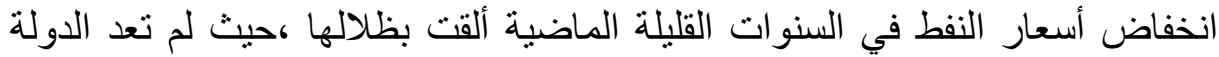
قادرة على مواصلة تمويل الجماعات المحلية فقررت إعتاقها ماليا،لتجد هذه الأخيرة

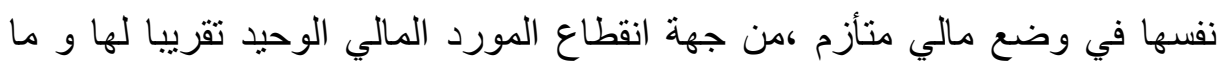

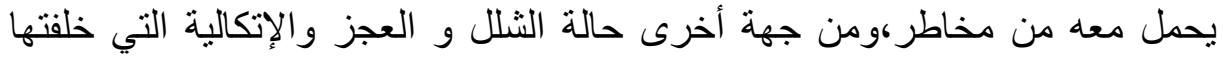

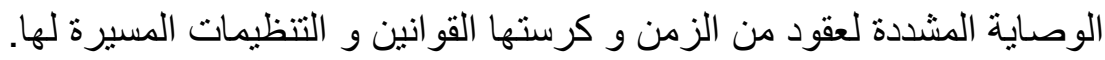

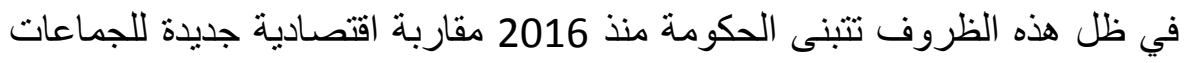

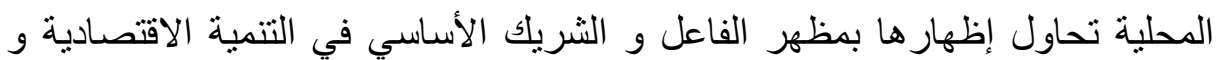

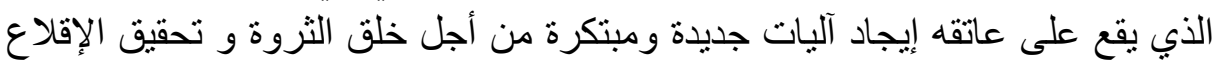

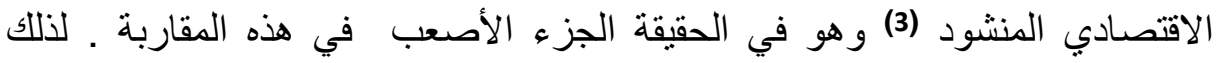

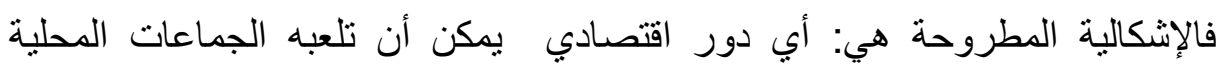

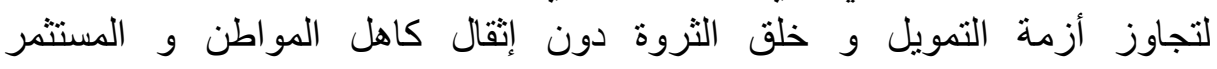

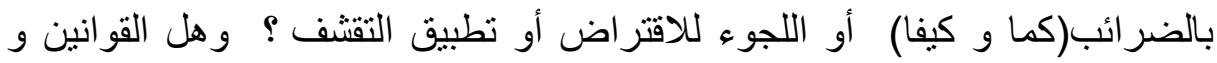

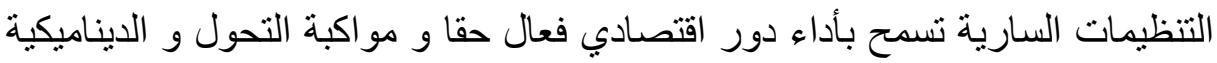

التي تشهدها الجماعات المحلية؟

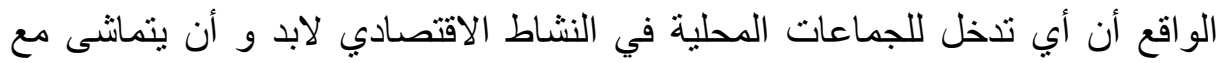

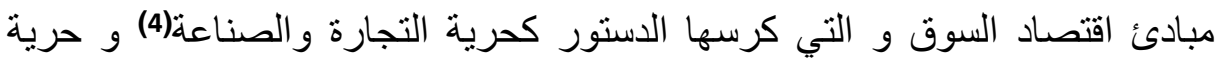

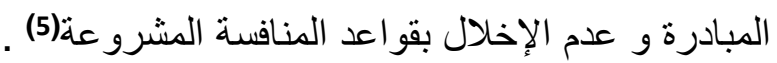

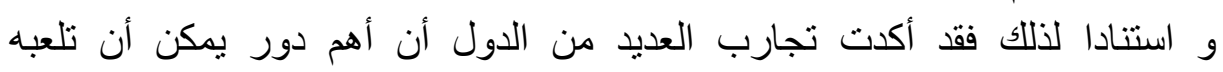

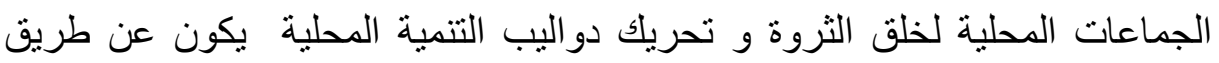

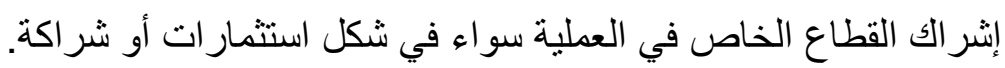
و عليه سوف نحاول الإجابة عن الإشكالية المطروحة أعلاه -وفق دراسة تحليلية - من خلال النقاط التالية: المبحث الأول: دور الجماعات المحلية في دعم الاستثمار المحلي. المبحث الثاني: الثر اكة مع القطاع الخاص:آفاق جديدة للتنمية المحلية . 


\section{المبحث الأول:دور الجماعات المحلية في دعم الاستثمار المحلي}

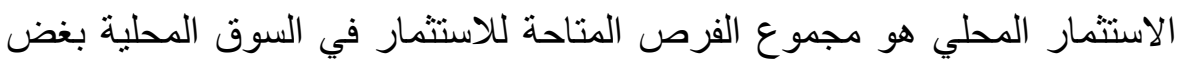

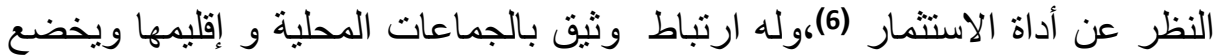

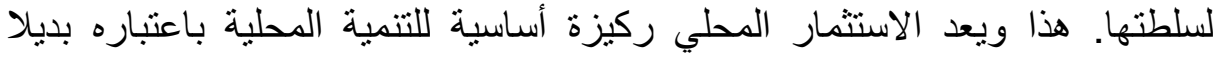

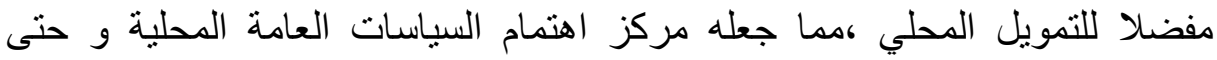
الوطنية بالنظر للايناميكية التنموية التي يحققها على جميع المستويات مرئ (المطلب الأول)

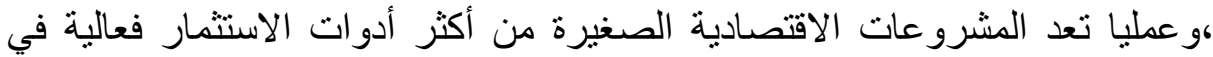

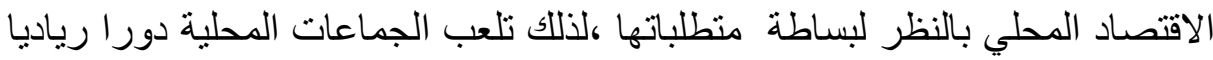
في تجسيد هذه المشاريع وذلك حسب الخصوصيات و المؤهلات التنموية لكل إقليم

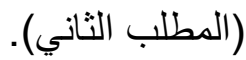

\section{المطلب الأول: أهمية الاستثمار المحلي}

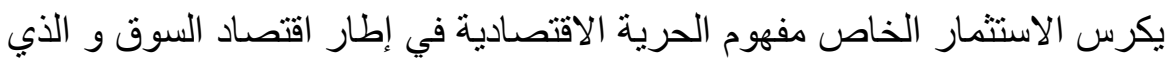

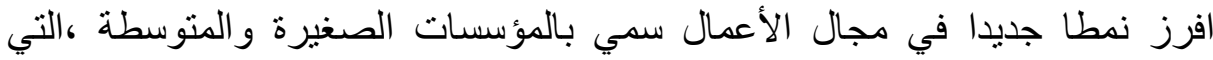

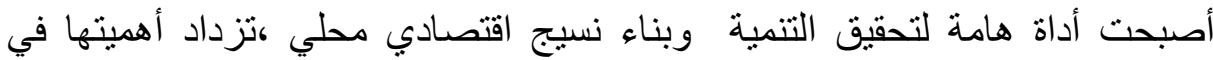

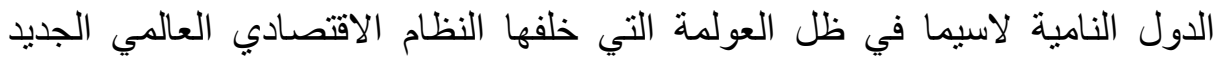

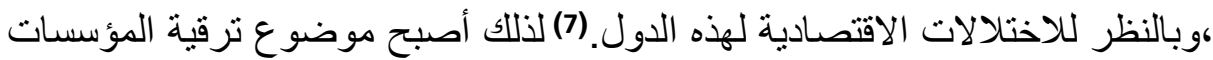

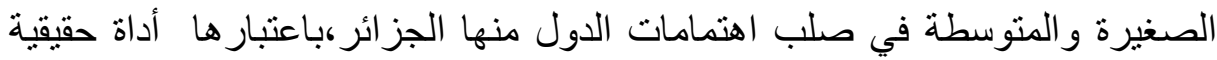
للتنمية المحلية وفاعلا هاما في الإستر اتيجية الوطنية للتنمية.

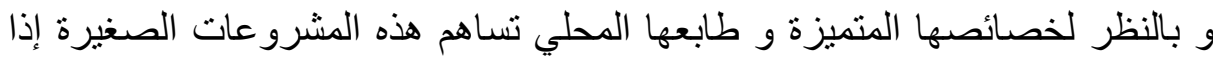

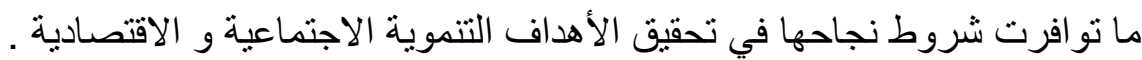
الفرع الأول: الأهداف الاجتماعية

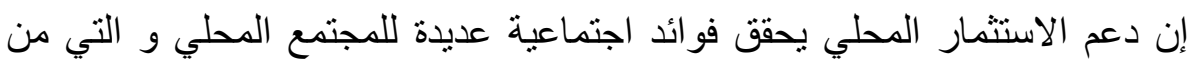
شانها خلق رضا لدى المواطن عن أداء الإدارة المحلية . هذا وقد أثبتت تجارب دول رائدة أن المشروعات المصغرة استطاعت تحقيق تتمية اجتماعية بطرق مختلفة أهمها:

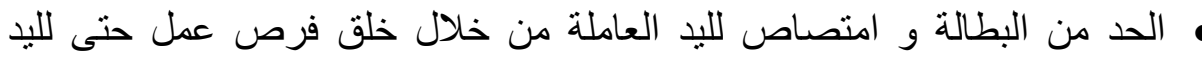

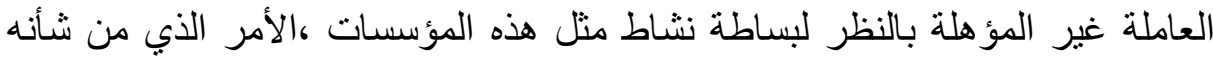

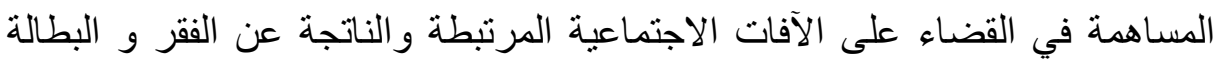

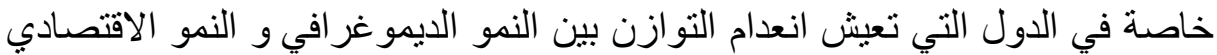

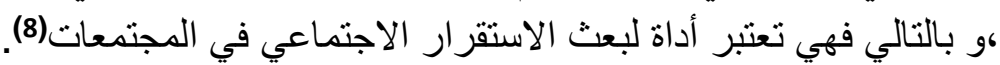

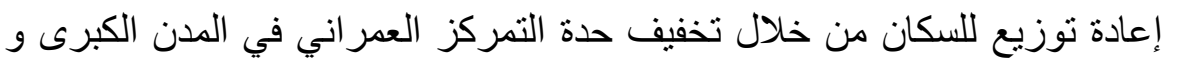

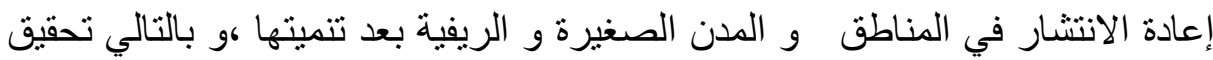
التوازن الجهوي (تنموياو ديمو غر افيا). • توجيه الاستثمار نحو بعض القطاعات التقليدية والحرفية من شأنه المساهمة في

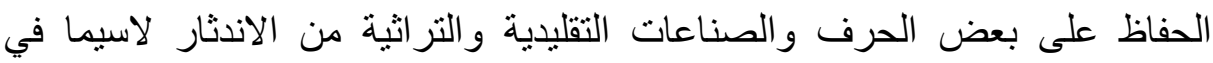
عصر العولمة الثقافية و بالتالي الحفاظ على خصوصية الأقاليم. 
هـ ترقية دور المرأة في المجتمع من خلال تتجيع المبادرات المقاولاتية النسوية ،و

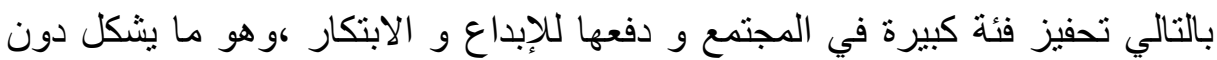
شك قيمة مضافة للتنمية المحلية . فيز فئة •الاستثمار في مجالات البيئة ونظافة المحيط و إعادة الرسكلة و الطاقات المتجددة

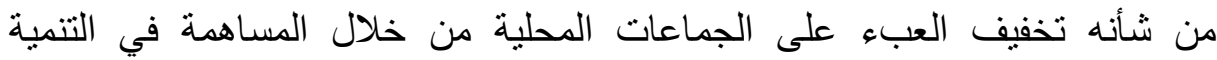
المستديمة عن طريق ما يعرف قانونا بالمسؤولية الاجتماعية للمؤسسات الاقتصادية

الفرع الثاني:الأهداف الاقتصادية تتعاظم الأهداف الاقتصادية المرجوة من إنثاء المؤسسات الصغيرة والمادة المتوسطة كآلية

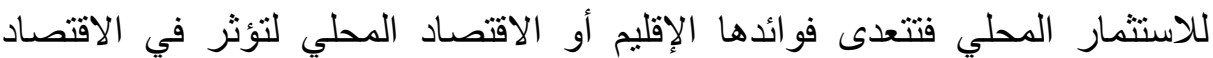
الوطني و التنمية الوطنية. فعلى المستوى المحلي يمكن لهذه المشروعات أن تعيد توزيع الدخل و تحقق العدالة

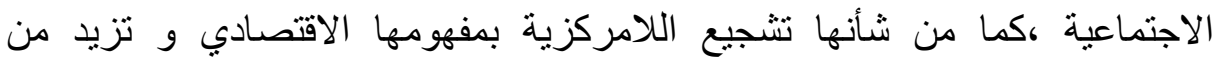

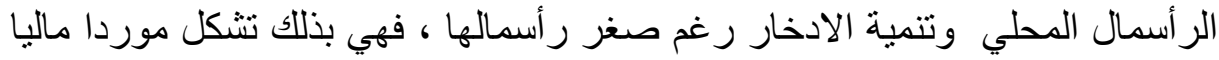

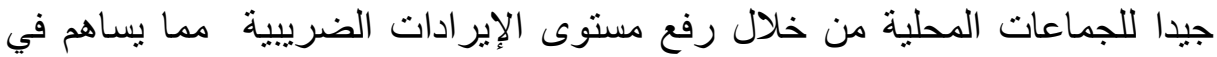

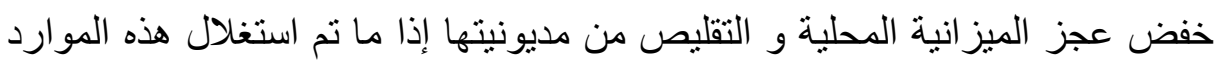
بشكل صحيح(10) بفن عجز النيز

من جهة أخرى الاستثمار المحلي من شأنه تلبية الحاجيات الاستهلاكية المحلية بفضل هاتل

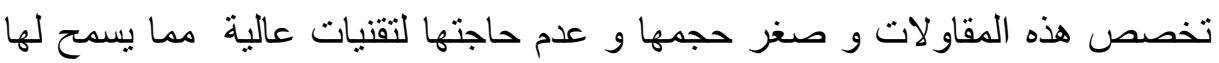

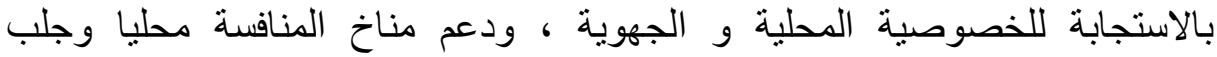

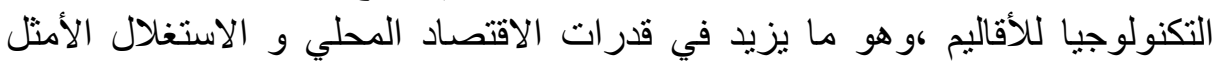

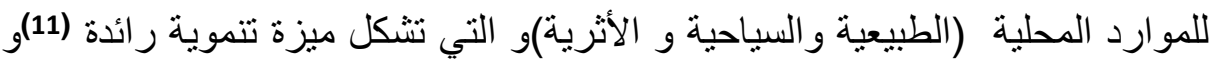

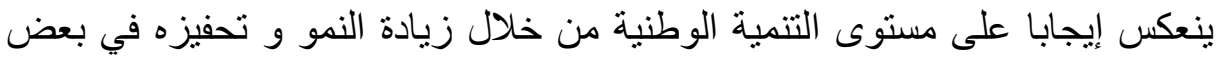

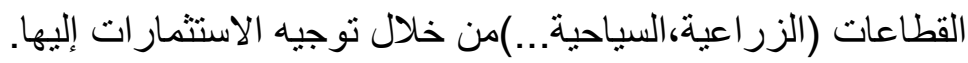

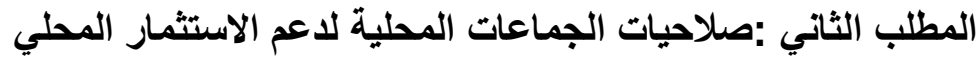

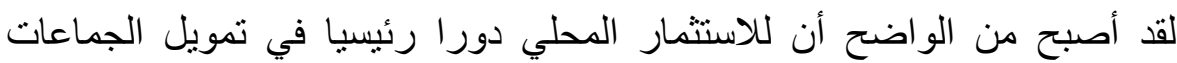

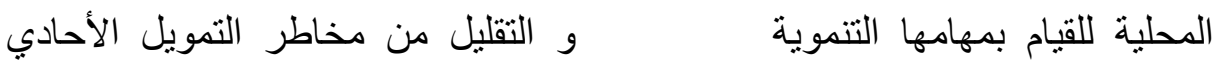

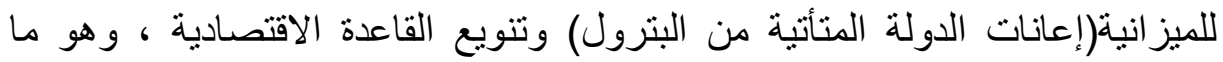
يقتضي تشجيع المبادر ات المحلية. و على هذا الأساس يتوجب على الجماعات المحلية تهيئة البيئة و المناخ الملائمين

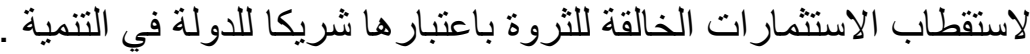

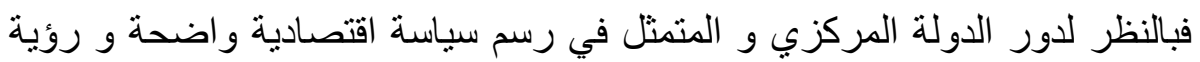

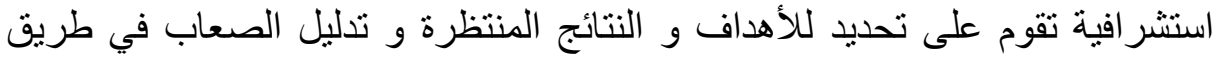
الاستثمار المحلي ،شهر قطاع المقاولات الصغيرة تطورا هاما عقب تتفيذ سياسات

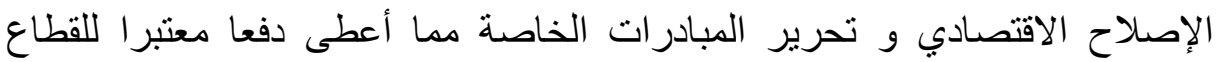

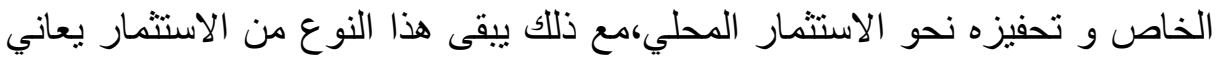

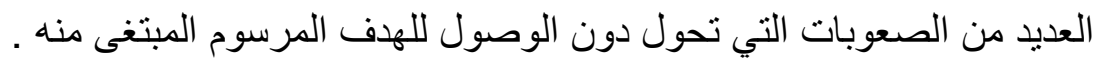


و قد أثتتت الدراسات القانونية و الاقتصادية أن مجمل العراقيل هي مالية و مادية

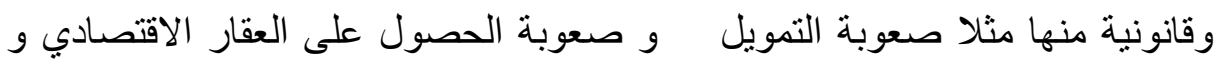
ثقل الإجراءات الإدارية،و صعوبة الحصول علده على المادة الأولية وارتفاع أسعارها

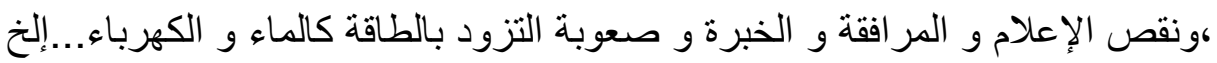

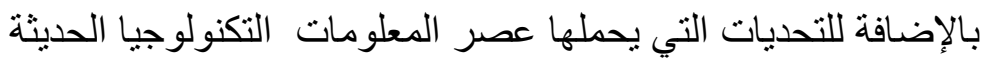

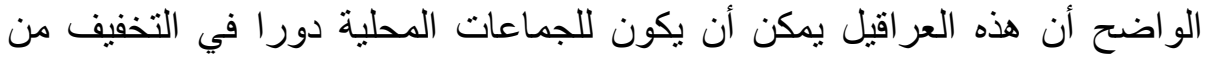

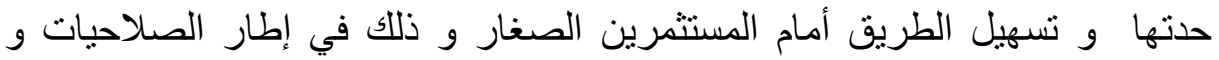
الإمكانيات الممنوحة لها من أجل تحفيز محيط الاستثمار المحلي.

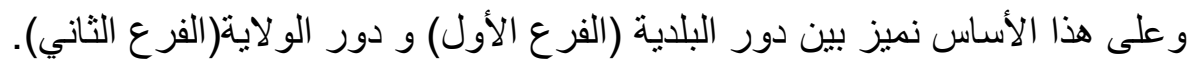
الفرع الأول :دور البلدية الاية تملك البلدية باعتبار ها جماعة إقليمية صلاحيات هامة لداعم الاستثمار المحلي في

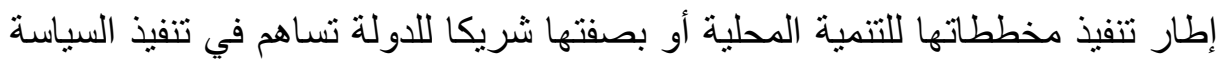

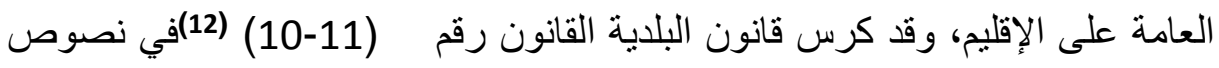

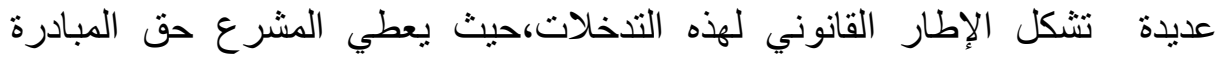

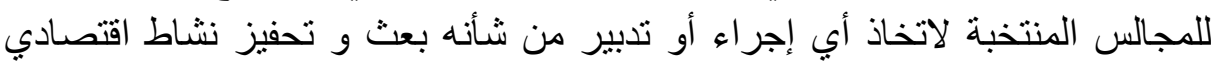

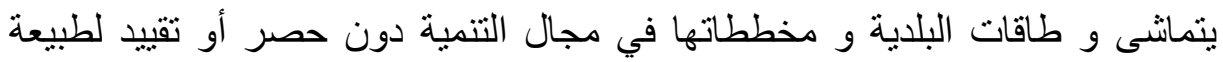

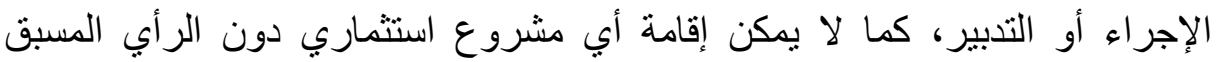
للمجلس الشعبي البلدي ( حسب نص التبر المادة 109).

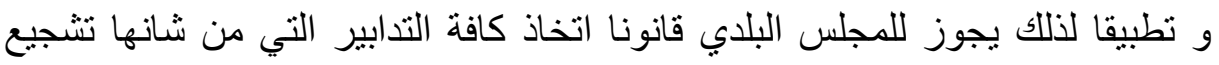
الاستثمار و ترقيته و توسيع قدر اتها السياحية و تشجيع المتعاملين المعنيين باستغلانلالها

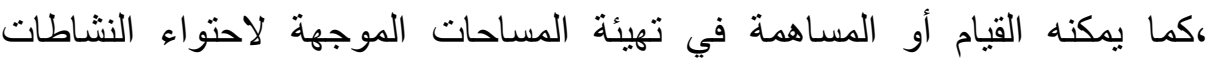
الاقتصادية أو التجارية أو الخدماتية (13) كما يسهر على الحئه الحفاظ على الوعاء الواء العقاري

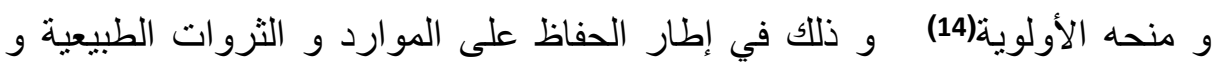
حسن استغلالها. و في سبيل تجسيد هذا الدور الاقتصادي على البلدية تعبئة مواردها و إحداث الداث

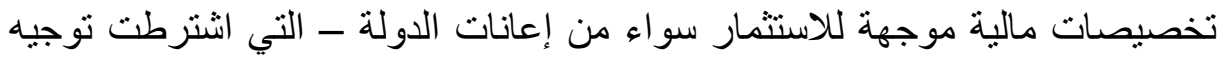

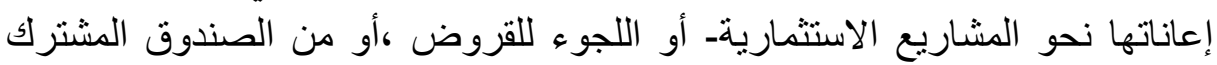
للجماعات المحلية، أو باقي إيرادات البلدية. وفي نفس السياق جاء القانون التوجيهي لتطوير المؤسسات الصغيرة و وات المتوسطة ـ

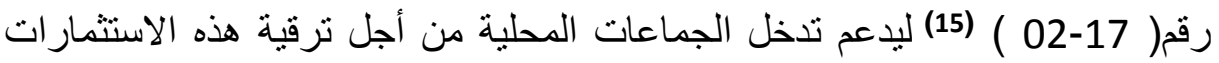

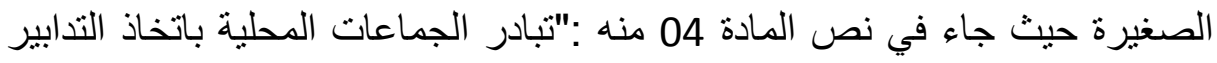

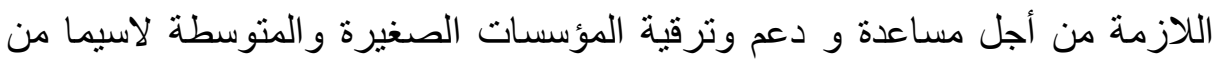

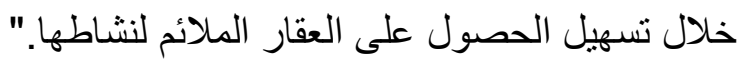

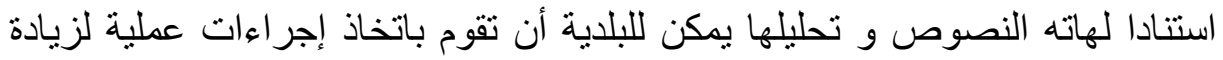

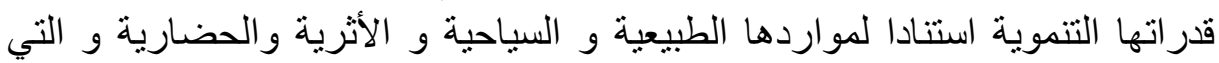

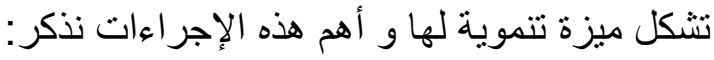

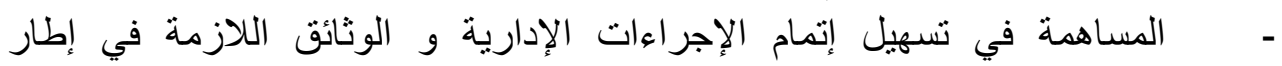

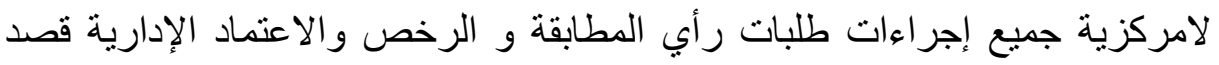




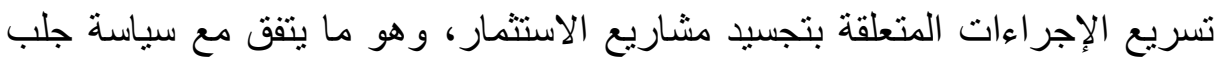

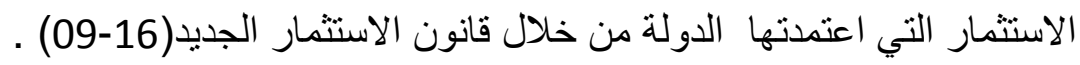

تطوير العرض العقاري الموجه للاستثمار بجميع أشكاله :صناعي ،سياحي الأني

،فلاحي غابي و ت تنميته و حمايته.

- ت تهيئة البنية التحتية للبلدية و جلب التكنولوجيا الحديثة لجلب الاستثمار ،و في هذا

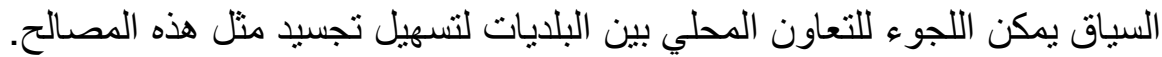

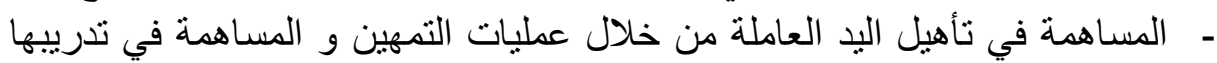
من خلال إعداد دورات تكوينية(16).

- المشاركة في عصرنة المؤسسات الاقتصادية المحلية وتحديد مجالاتها الاستثمارية

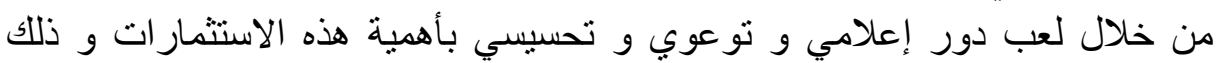

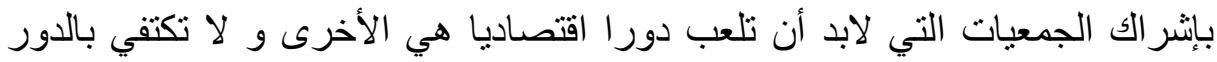

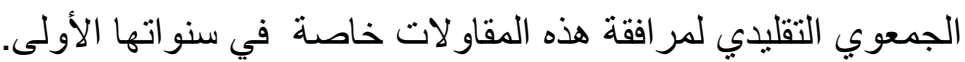
- إعطاء أولوية للتسويق المحلي للموارد و المؤهلات الطبيعية و السياحية و الثقافية

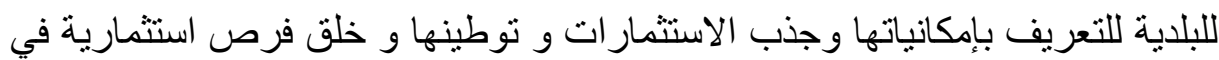
مختلف القطاعات،واستغلال الإدارة الإلكترونية للترويج لذابت اللك.

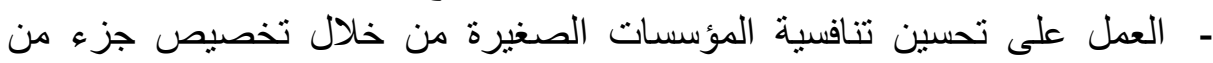

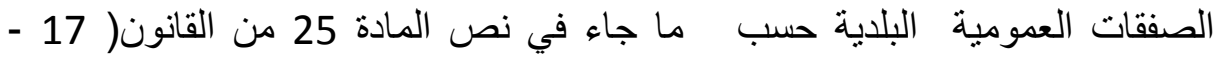

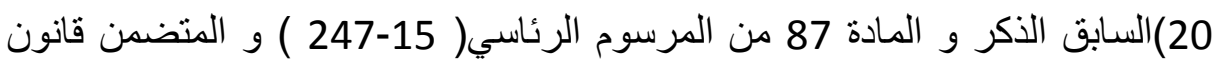
الصفقات العمومية و تفويضات المرفق العام(17)،و كذلك المادة 23 من المرسئ المرسوم التنفيذي المتعلق بتفويضات المرفق العام( 18-199)(18) التي تلزم بمنح الأولوية لهاته المؤسسات في منح التقويض. كما يمكن للجماعات المحلية الاستعانة بالر أي الاستشاري لمجلس المنافسة في هذا

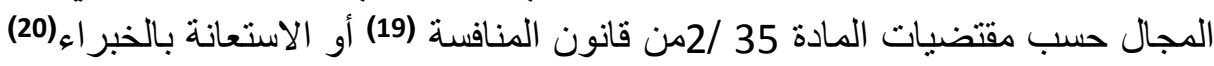

مع ذلك و حتى يتم تفعيل هذه التدابير لابد من تضمينها في خطط و موازنات

قصارى القول أن للبلدية دور كبير في إنجاح أي رؤية استثمارية تسمح بتفعيل

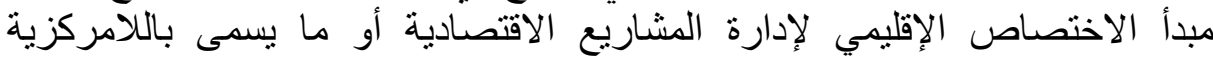

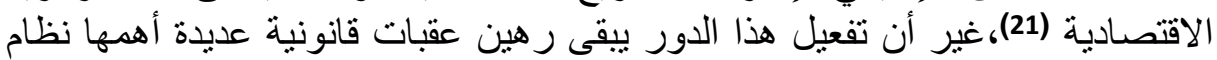

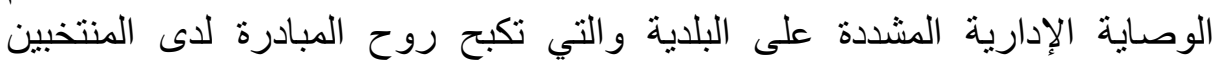

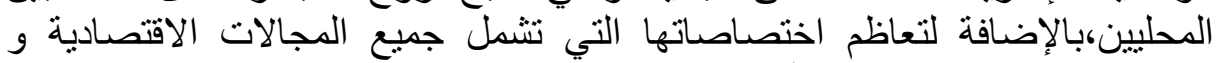

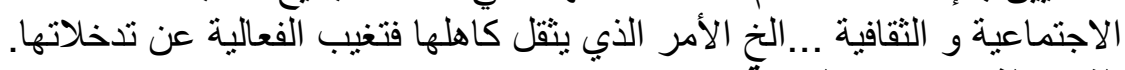
الفرع الثاني : دور الولايةّة في هذا الصدد يجب التور التمبيز بين صاية صلاحيات المجلس الشعبي الولائي كهيئة تمثيلية تدأولية(أولا) و دور الو الوالي كهيئة عدم تركيز للتنفيذ(ثانيا). أولا: صلاحيات المجلس الثعبي الولائي

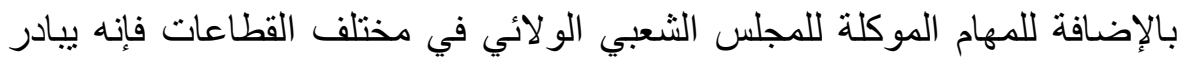

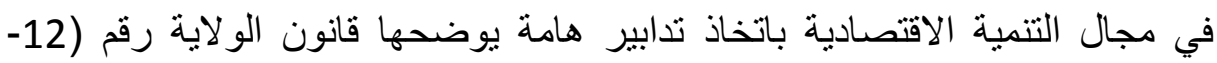


خصوصياتها الطبيعية والجغر افية و مؤ هلاتها في إطار مخططات التنمية التي يعدها.

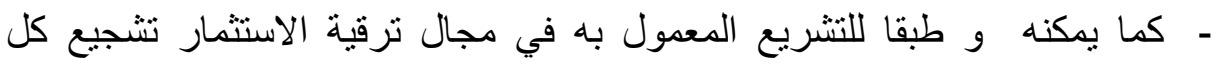

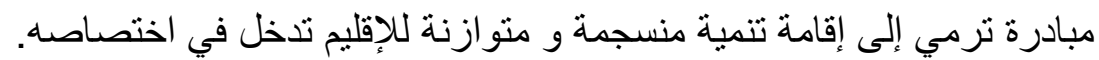

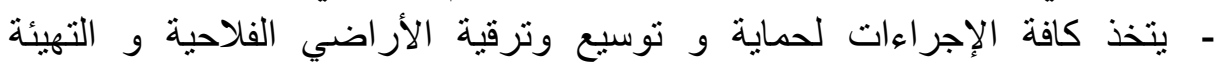
و التجهيز الريفي (23) و هو ما يعطي دفعا للاستثمار في المجال الفلاحي.

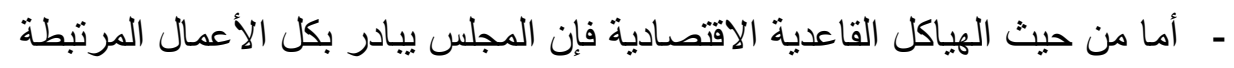

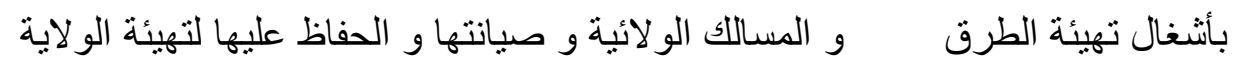
كمنطقة جذب للاستثمار . - وفي ذات السياق يعمل المجلس على ترقية و تنمية هياكل استقبال الاستثمار ات(24).

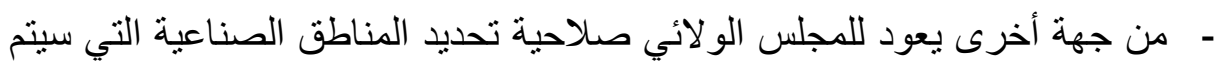

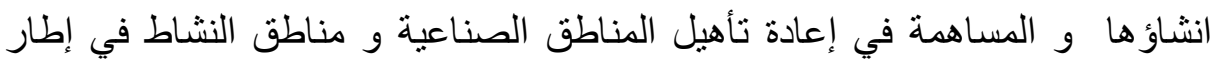

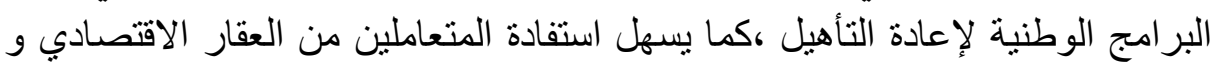

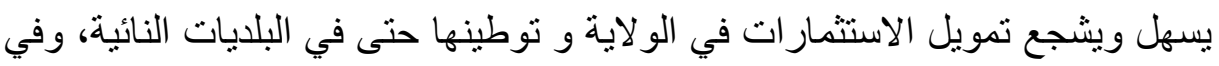

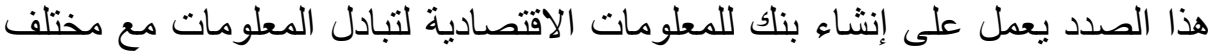
الهيئات . التذات

ثانيا :الدور الاقتصادي للوالي

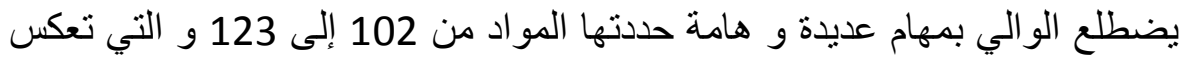

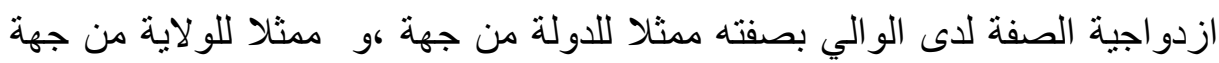

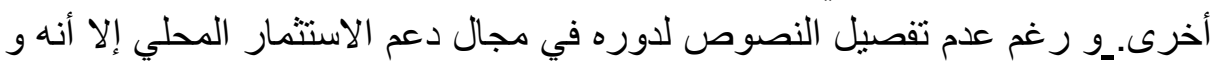

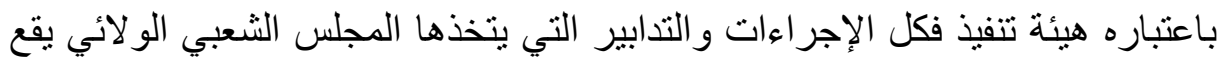

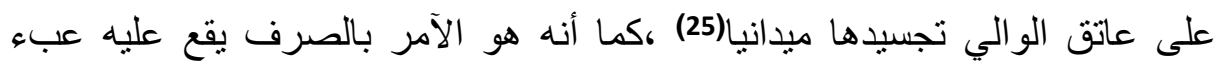

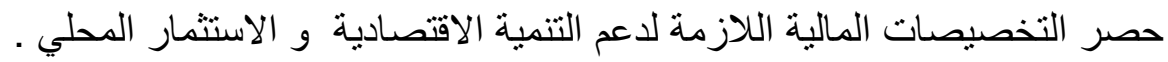

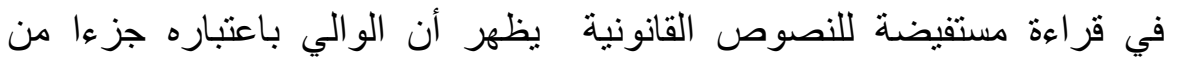

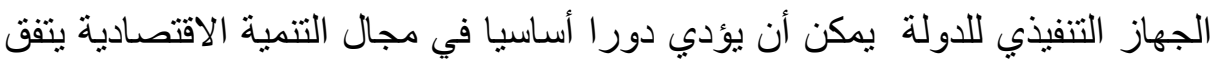

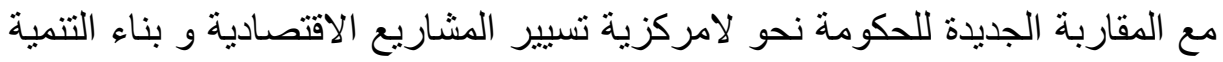

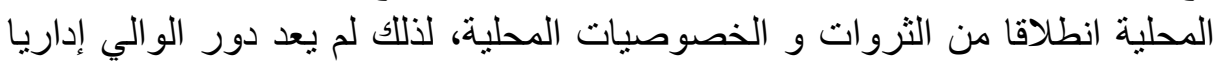

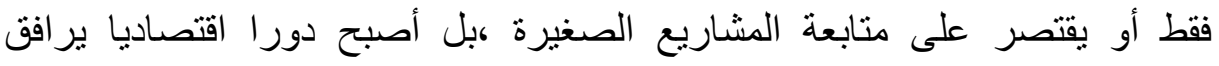

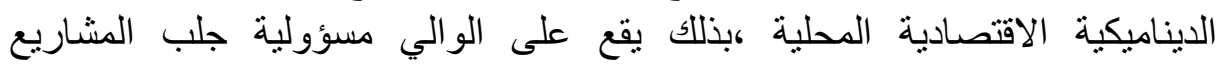

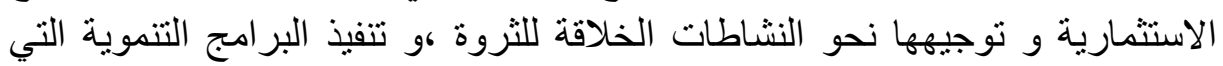

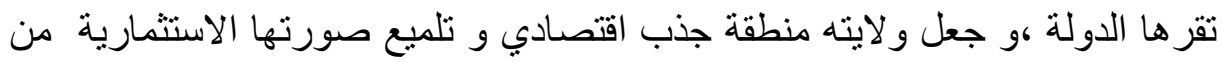

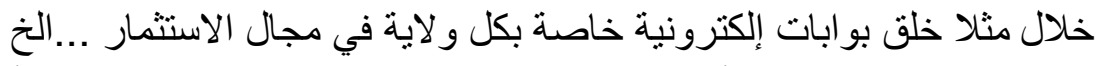

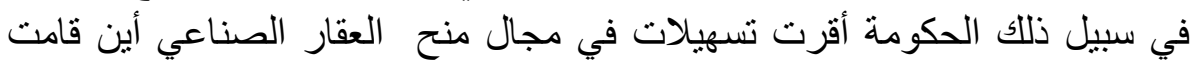

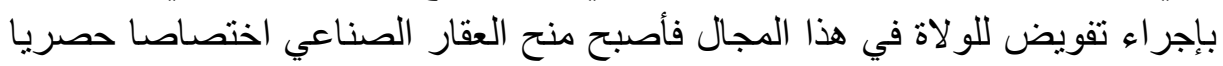

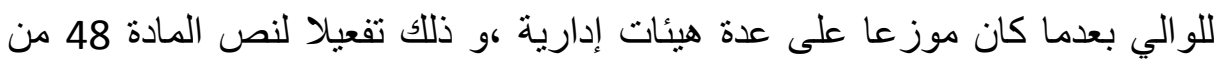

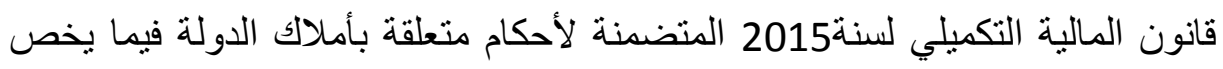

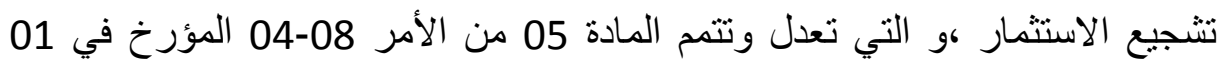

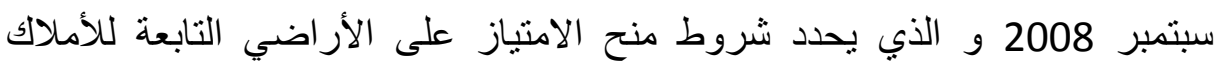


الخاصة للدولة و الموجهة لانجاز مشاريع استثمارية و التي جاء فيها :" بموجب هذه

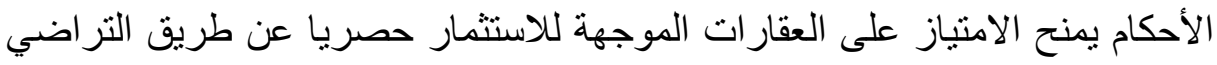

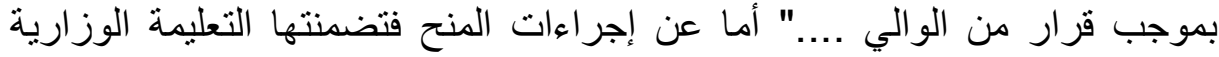

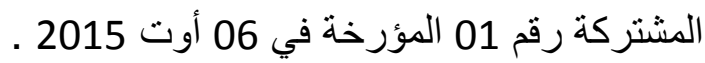

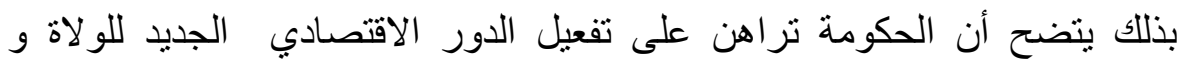

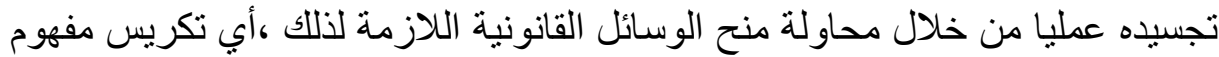

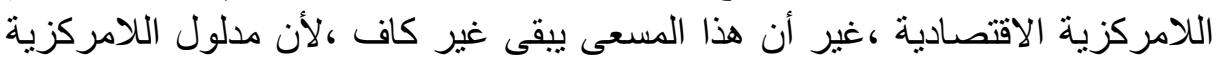

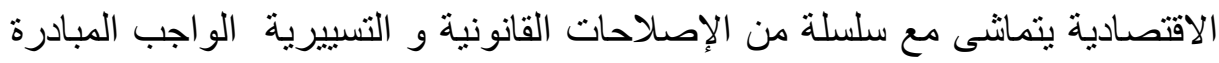

المبحث الثاني: الثراكة مع القطاع الخاص :آفات جديدة للتنمية المحلية

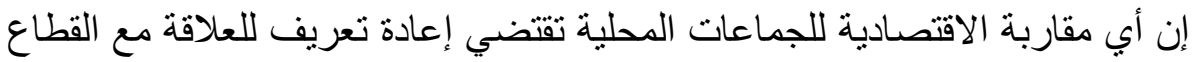

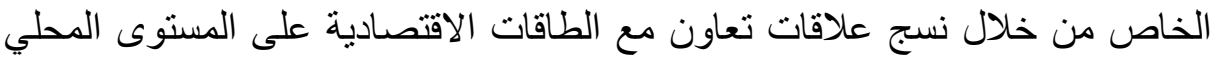

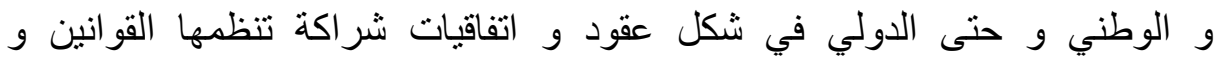

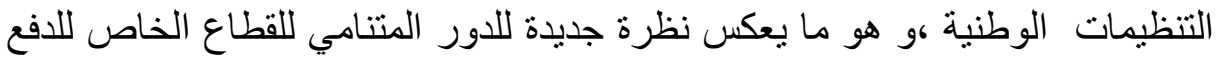

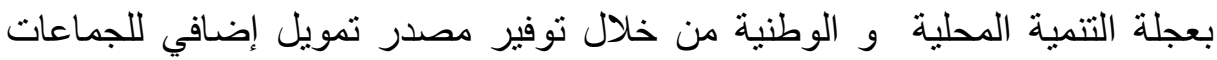

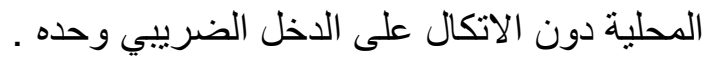

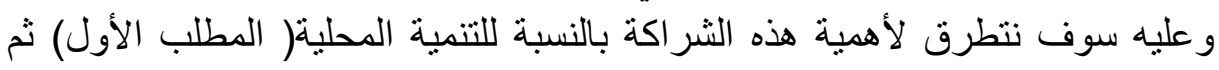
لأهم أثكال الثراكة بين الجماعات المحلية و القطاع الخاص ،ور أفق تطويرهال

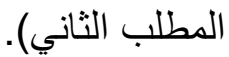

المطلب الأول:أهمية الثراكة مع القطاع الخاص في تمويل التنمية المحلية

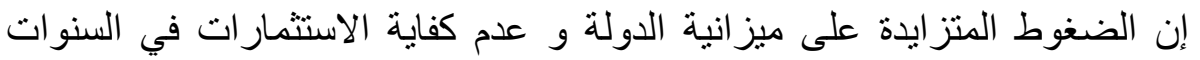

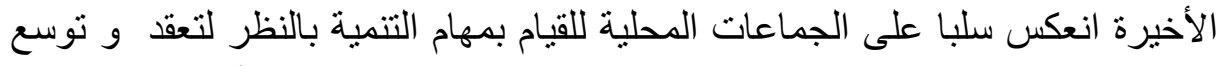

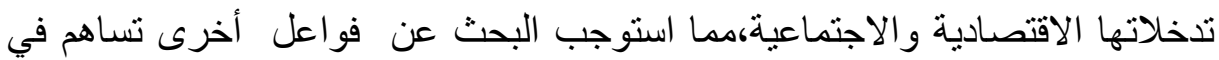

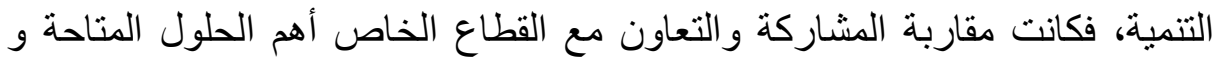

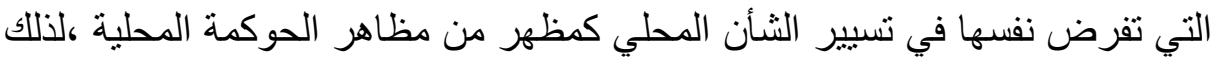

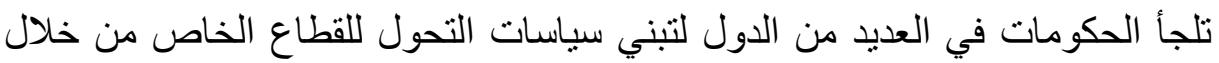
إعطاء دور أكبر لهذا القطاع في عملية تقديم الخدمات و التنمية المحلية و إدخال

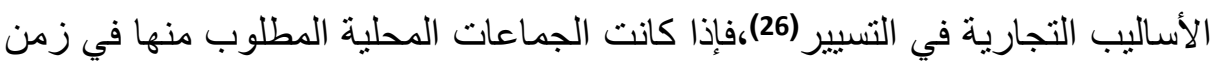

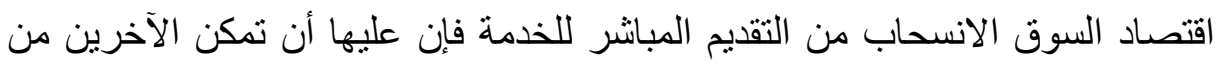

$$
\text { تقديم هذه الخدمات(27) }
$$

و عليه تحقق الثر اكة مكاسب و ايجابيات عديدة محليا و وطنيا إذا تم تتظيمها بشكل

فالمعلوم أن الأسلوب التعاقدي هو تأكيد على البعد الاقتصادي في التسبير ،من شأنه

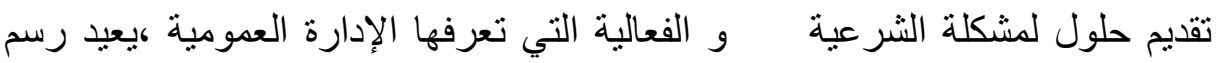

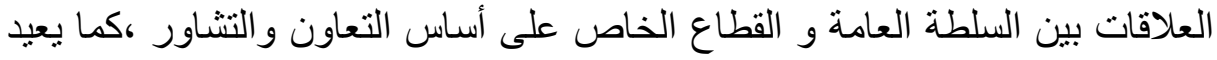

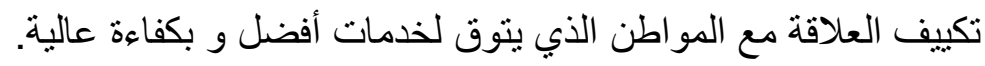

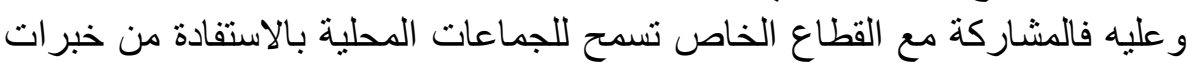

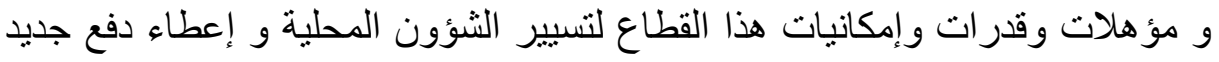


للمر افق العامة و الخدمة العمومية التي لم تعد حكرا على الإدارة العامة ،بل يمكن

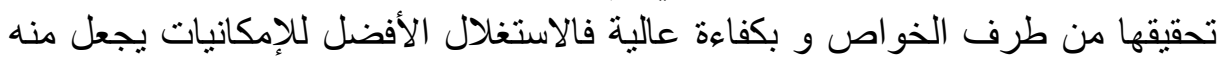

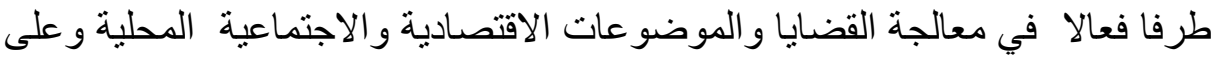

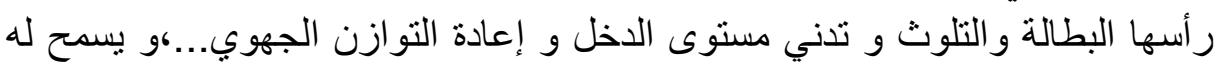

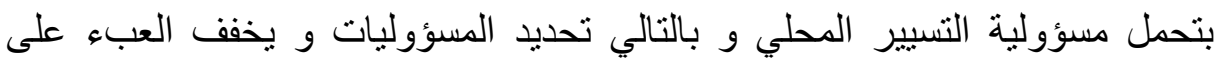

الجماعات المحلية في مجال التنمية ،كما يخفف الوصاية ولية عليها (28). و عليه فالثر اكة مع القطاع الخاص تخلق ديناميكية محلية و تجعل من مسألة

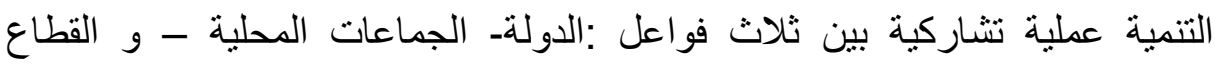
الخاص و تلغي فكرة الفاعل الوحيد(الدولة) التي تكتفي بوضع السياسات العامة و ولاعات

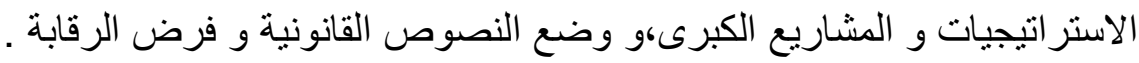

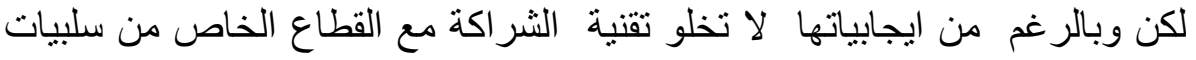

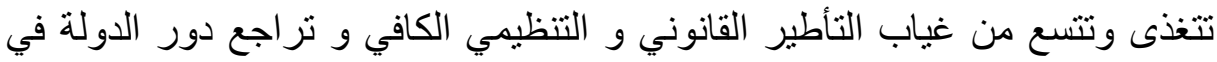

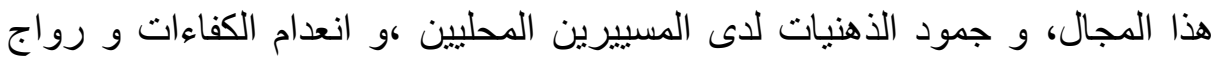

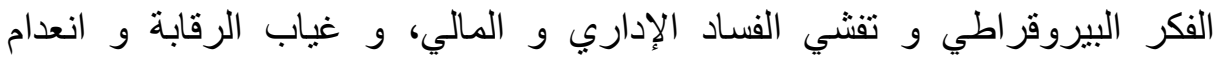

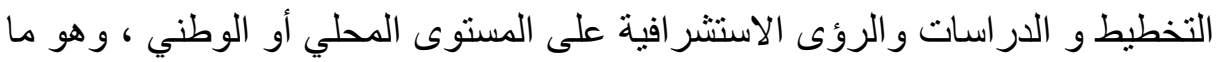
يستدعي إصلاح جذري وسريع لمناهج تسيير الجماعات المحلية.

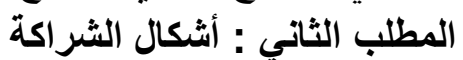
الو اقع أن ألثر اكة مع القطاع الخاص مرت الثراكة بمر احل تطورية أملتها معطيات عديدة

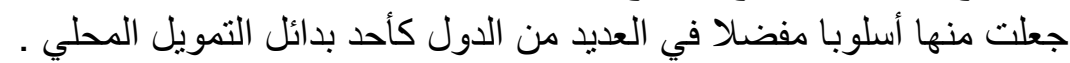

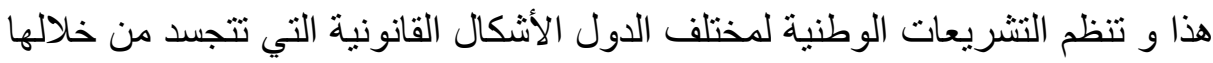

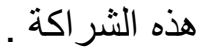

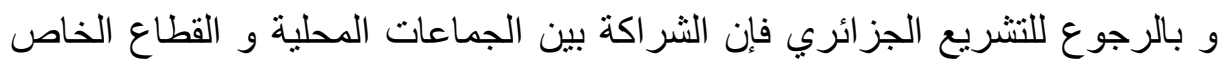

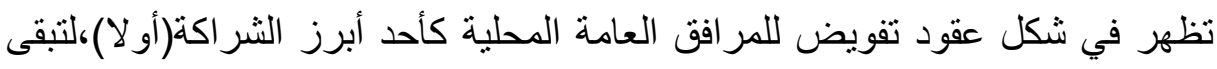

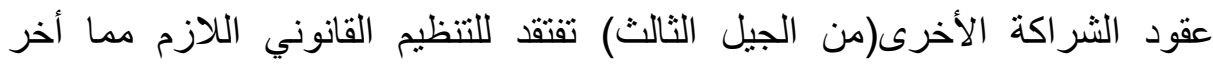
ظهور ها وتطور ها في الجزائر(ثانيا).

أولا : تفويض المرفق العام المحلي أبرز أثكال الثراكة

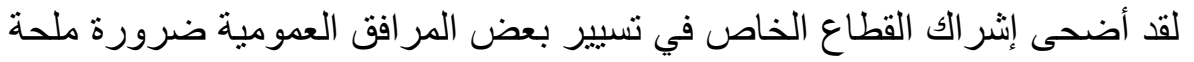

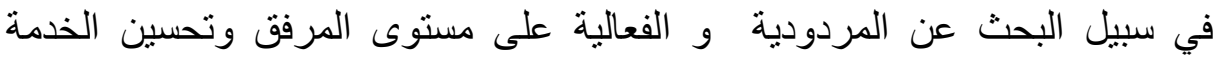

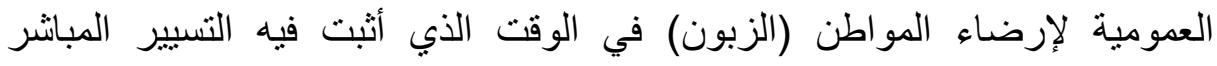

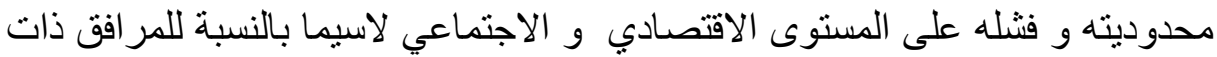

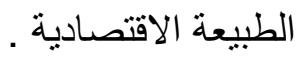
وقد ارتبط تفويض المرافق كتقنية ليبرالية(29) بالدور الجديد للاولة الذي يقوم على

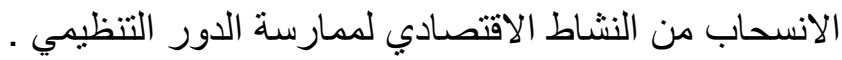

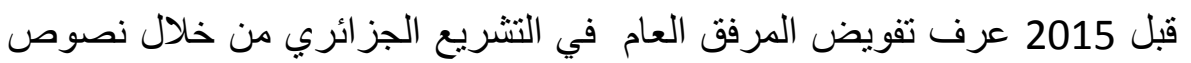

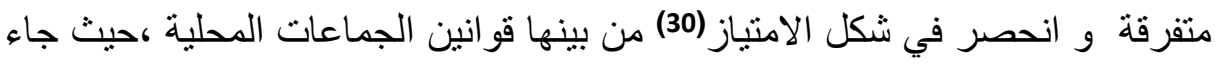

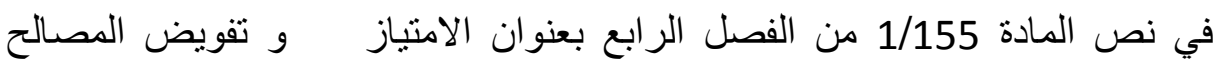

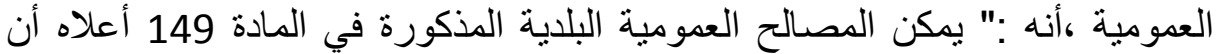
تكون محل امتياز طبقا للتنظيم الساري المفعول". 
و عليه فالمشرع من خلال هذا النص من جهة يحصر المرافق البلدية التي يمكن أن

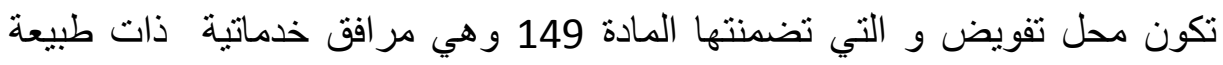
تجارية يمكن أن تكون محل للمنافسة(31)، ومن جهة أخرى يترك للبلدية السلطة ولئة التقديرية في إخضاع هذه المر افق للطرق التقليدية للتسيير أم تفويضها حسب إنب إمكانياتها

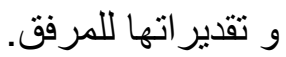

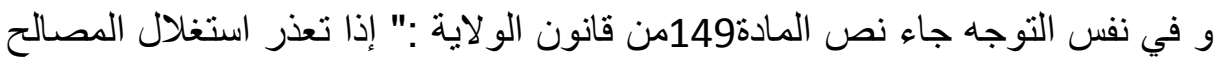

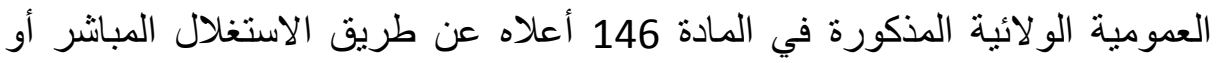
مؤسسة ،فإنه يمكن المجلس الثعبي الولائي الترخيص باستغلالها عن طريق الألهاه الامتياز

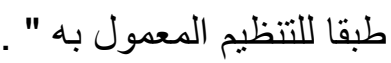
هذه النصوص القليلة و المبعثرة تعكس توجها ضعيفا من قبل الدولة للثر اكة في تسبير

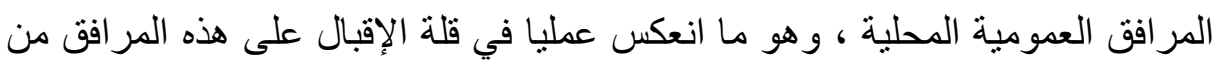
قبل الخواص (32). لكن بعد 2015 و بصدور المرسوم الرئاسي( 15-247 ) المتضمن تنظيم الصفقات العمومية و تفويضات المرفق العام، والذي جاء ليسد فراغا في التشريع الجزائري التئي

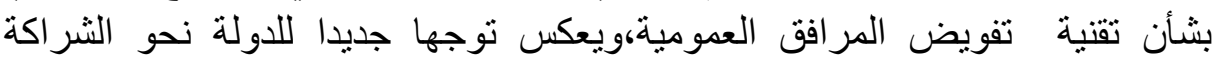

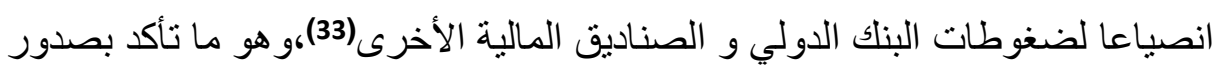

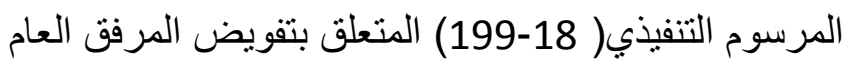

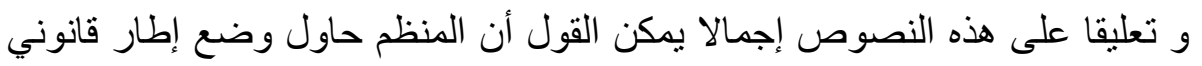

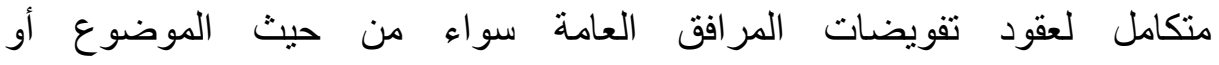

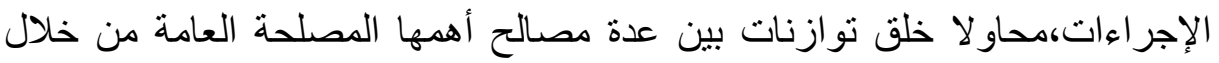

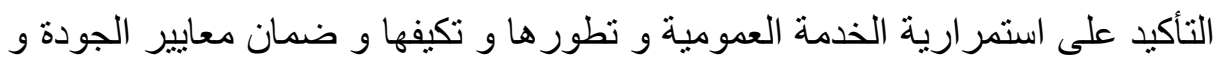

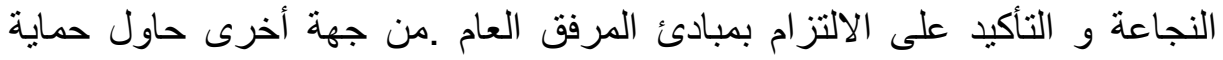

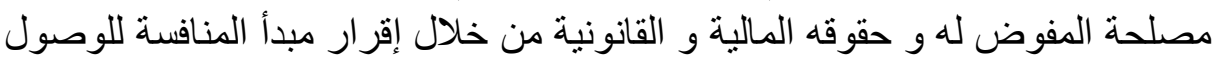

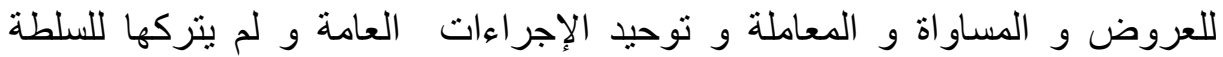

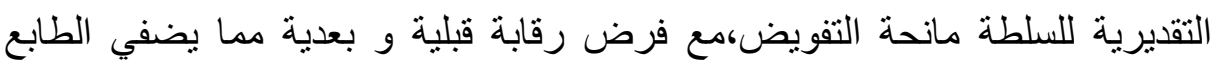

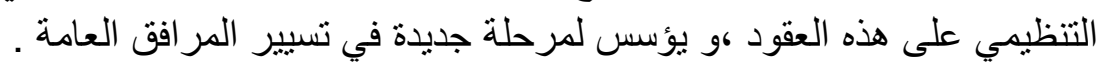

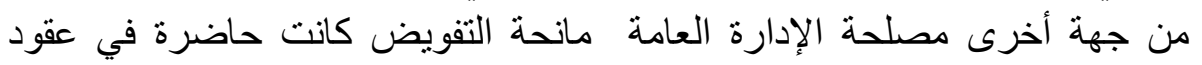
التفويض التي أضحت أحد مصادر الجباية المحلية ،و تحد من تضخم الإدة النفقات و الأعباء المالية بالإضافة لتخفيف العبء في تسيير مثل هذه المر افق وتحمل مسؤوليتها

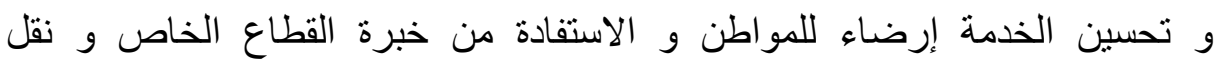

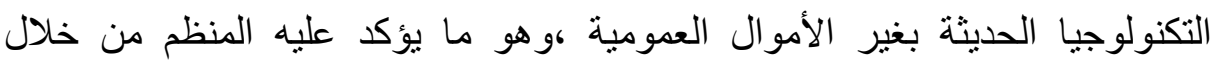

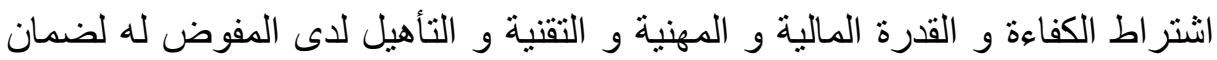

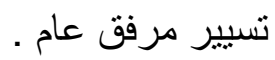
ما يمكن ملاحظته أيضا أن المنظم من خلال هذه النصوص حاول ضبط الإطار

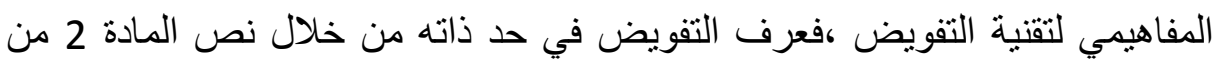
المرسوم التنفيذي( 18-199 ) و المبادئ التي تحكم اتفاقية التفويض ،كما حدد طبئ في فئه القانونية من خلال نص المادة 6 على أنه عقد إداري بما ينرتب على على ذللك من نتائج 
خاصة القانون الواجب التطبيق( القانون العام) و القضاء المختص في حال النزاع(القضاء الإداري).

من جهة أخرى جاء بأثكال جديدة لتفويض المرفق العام المحلي و حدد مفهومها

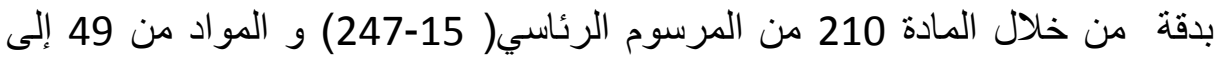
56 من المرسوم التنفيذي( 18-199 )فإلى جانب الامتياز هناك الإيجار و الوكالة المحفزة و عقد التسيير، وقد ميز بينها حسب مستوى التفويض و الخطر الذبي يتحمله المفوض له و رقابة السلطة المفوضة بالشكل الناليز

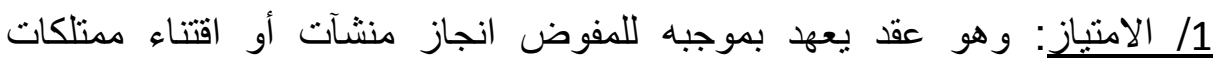

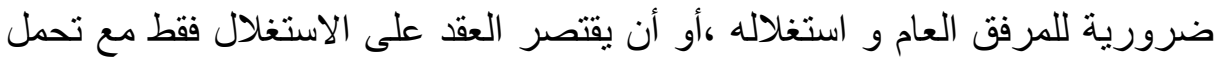
المفوض له مسؤولية الاستخلال و تمويل و اقتناء ممتلكات المرفق مقابل أتاوى يدفعها

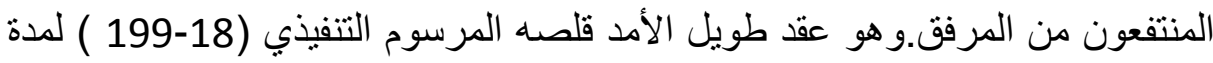

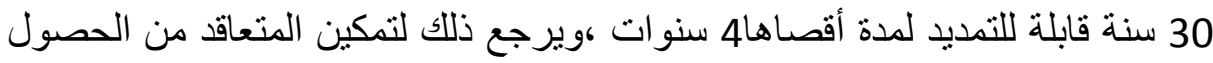

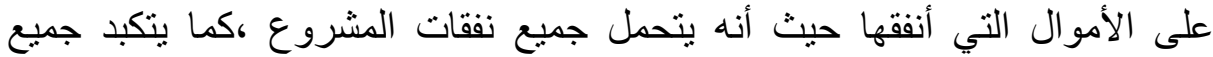

مخاطره ،كما تسمح له هذه المدة بتحقيق ربح معقول (34).

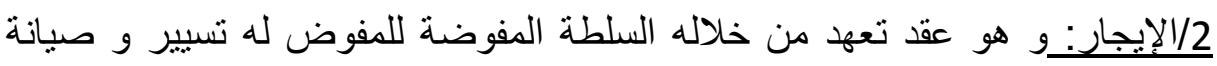
المرفق مقابل أتاوى سنوية يدفعها لها ،على أن يتحمل كل المخاطر الناجمة عن التسبير و تحت رقابة جزئية للسلطة المفوضة ،من جهتها تمول السلطة المفوضة إقامة

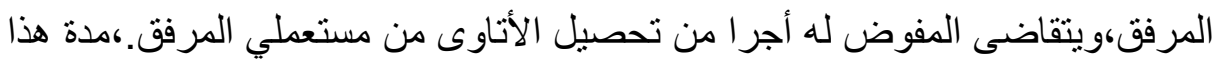
العقد 15 سنة كحد أقصى على أن تمدد استثنائيا ثلاث سنوات كأقات منى تقدير مرة

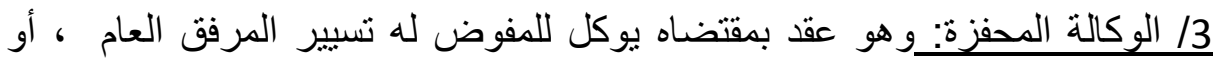

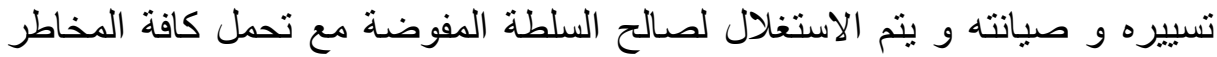
التجارية ،على أن تتحمل السلطة مانحة التفويض تمويل المرفق و تحتفظ بإدارته

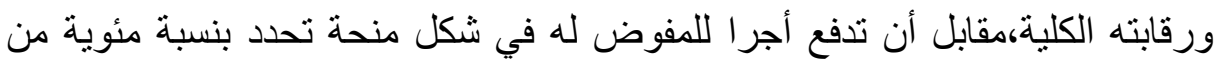

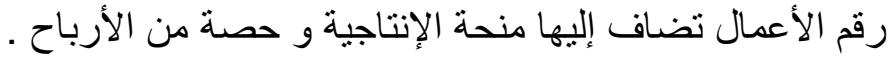

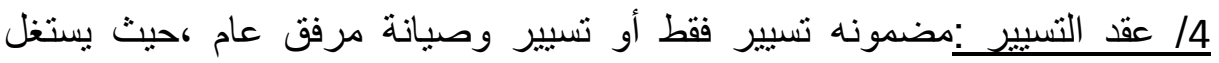

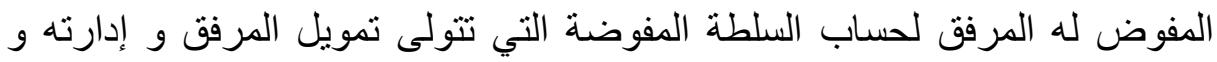
رقابته الكلية،كما تدفع له أجر ذلك في شكل منحة،مدة العقد قصبرة مقارنة بياقي

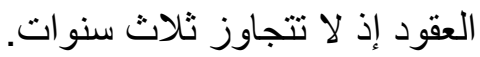
ثانيا :عقود الشراكة

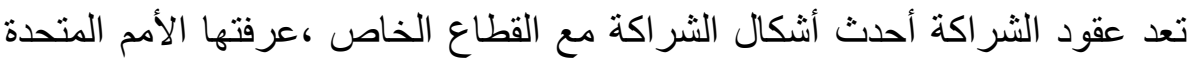

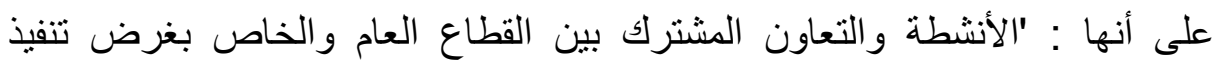
المشروعات الكبرى،بحيث تكون الموارد و الإمكانيات لكلا القطاعين مستخدمة معا

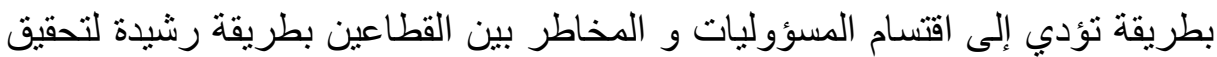

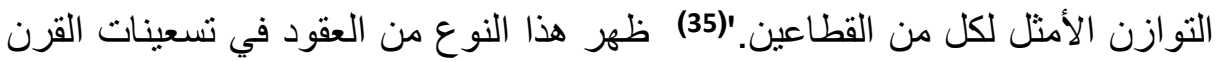

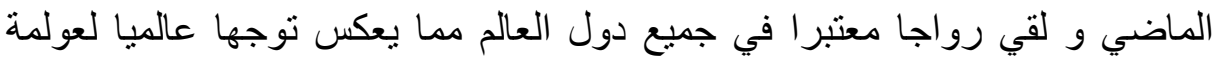

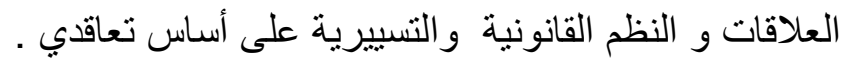


تسمح هذه العقود للدول و بخاصة النامية بتنفيذ المشروعات الكبرى عموما كالبنية

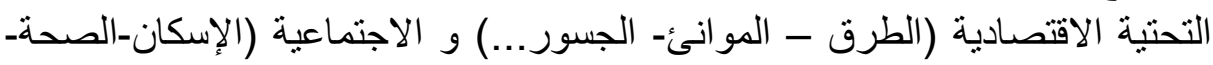

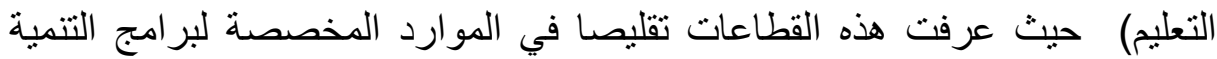

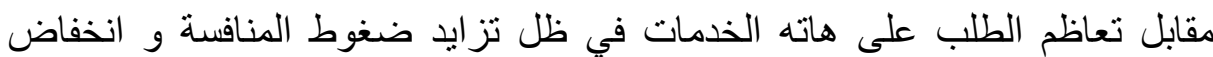

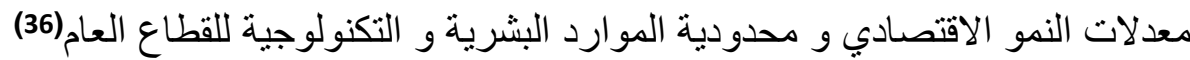
و في ظل هذه المعطيات أصبح القطاع الخاص حسب النظرية الاقتصادية هو "

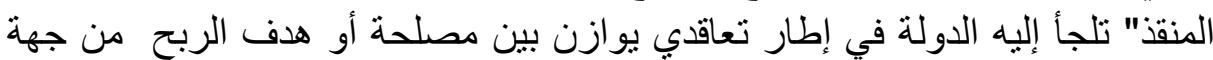

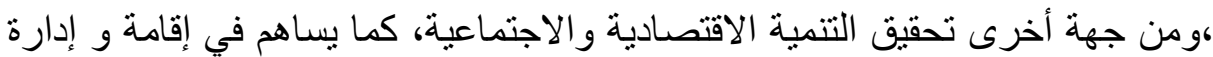

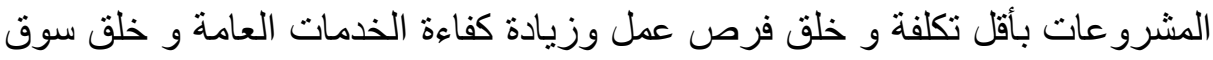

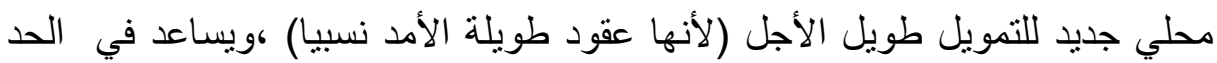

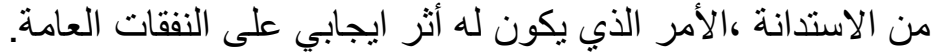

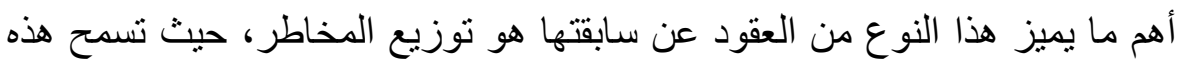

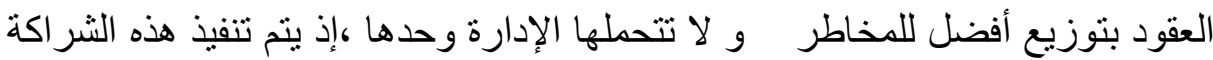

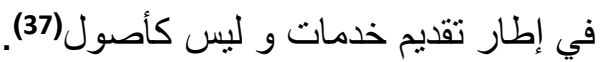

قانونيا يحتاج التفعيل العملي لهذه التقنية لتنظيم قانوني محكم لضمان لفان مختلف

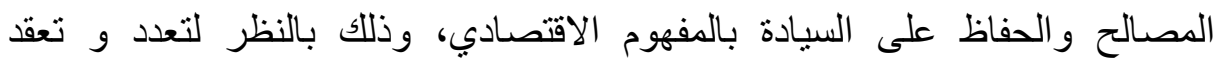
الجو انب الاقتصادية و القانونية والاجتماعية لهذه العقود ليس باعتبار ها أداة للتمويل فقط،بل كطريقة للتسيير الجديد.

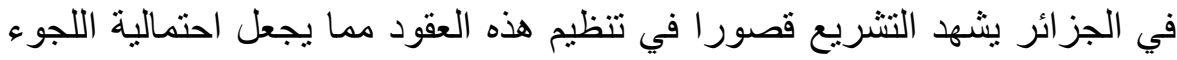
إليها من قبل الجماعات المحلية أمر سابق لأوانه رغم أن التوجه العام للدولة لا يتنافى التهاء

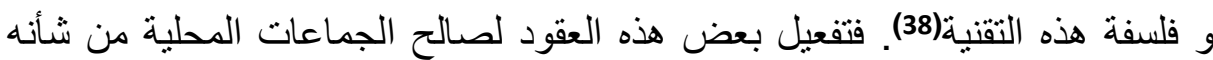

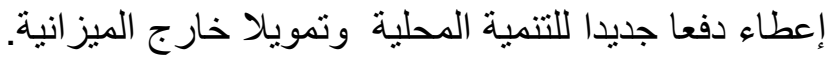

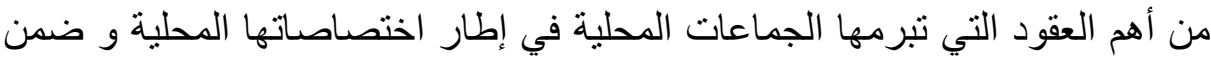

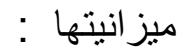
1 / عقود الإدارة: وينصب موضوع العقد على إدارة أو تسيير مؤسسة أو هيئة

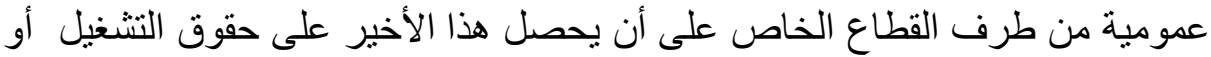

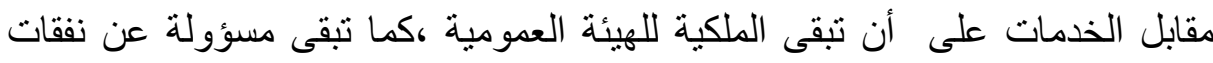

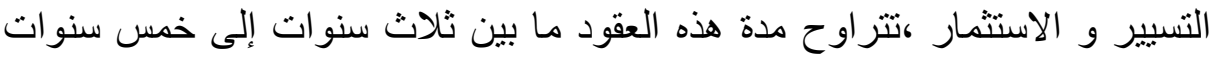

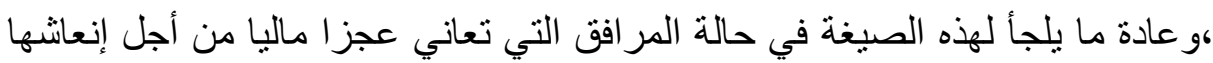

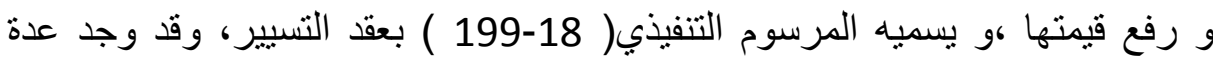
تطبيقات في دول عديدة و حقق نجاحا في عدة مرافق كمرفق الاتصالات و البريد

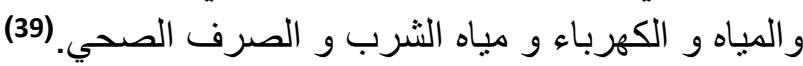
2/عقود الخدمة: وهي عقود موضوعها تقديم خدمات يتم الاتفاق عليها ، و هي عقود

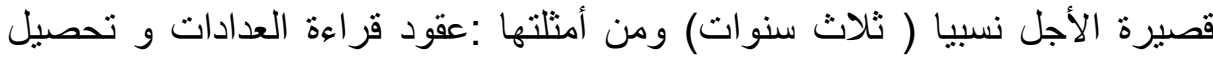
الفواتير، وتجديد شبكات مياه الثرب أو الصرف ون ، وقد وقد أثنتت نجاعتها في العديد من 
أما العقود المتبقية كعقد (BOT) البناء و التشغيل ونقل الملكية و عقد) BOOT

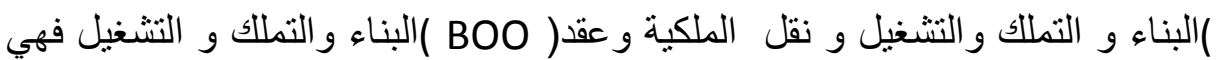
عقود تقع على مشاريع ضخمة ذات صبغة وطنية تخرج عن اختصاص الجماعات

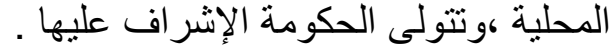

\section{الخاتمة}

إن العمل التنموي هو عمل شامل و مستمر في الزمن ،لذلك فإن أبي تدخل

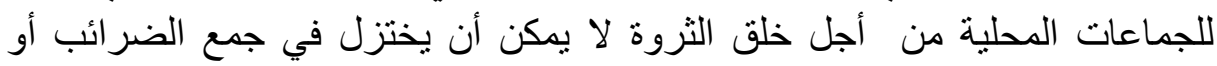

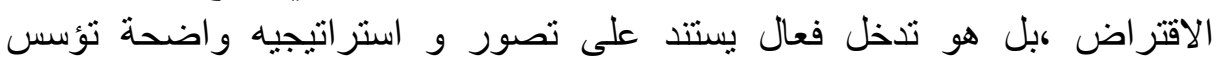
لاقتصاد محلي تلعب فيه هذه الهيئات دورا أساسيا من خلال الاعتماد على المؤهلات و الخصوصيات التنموية التي تزخر بها لجلب الاستثمار المجدي و توطينه و توجيها لتوليه

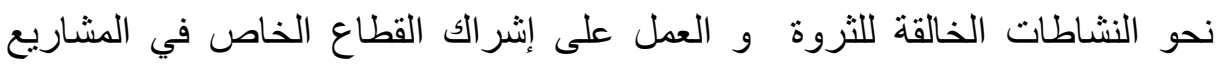
التنموية كفاعل محوري للافع بعجلة التنمية المحلية .

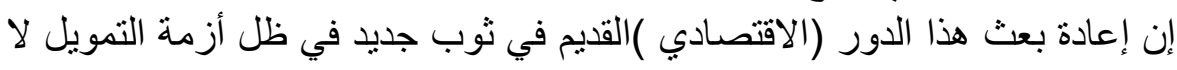

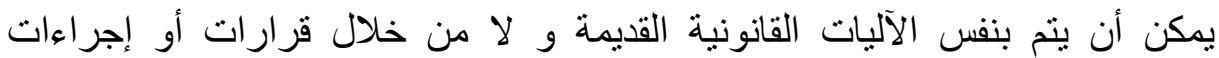
استعجاليه،بل من خلال الإسراع بإصلاحات جوهرية و مراجعة المنظومة القانونية

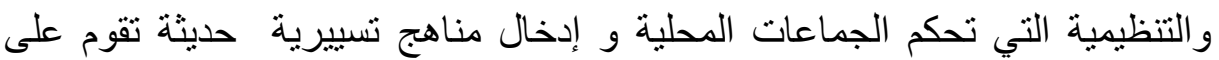

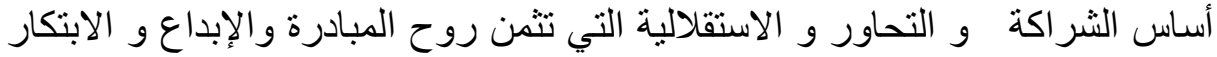
لاى الجماعات المحلية في الجزائر.

قائمة الهوامش و المراجع 1- للمزيد من التفصيل راجع:زبيري رمضان،العولمة و البنى الوظائفية الجديدة

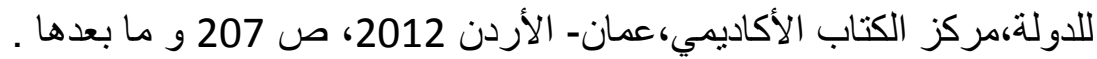

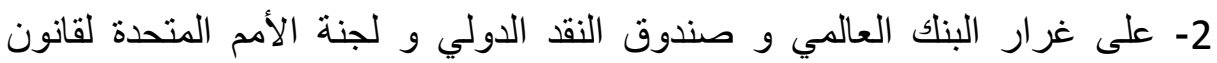
التجارة الدولية uncitral و مؤسسة منظمة الأمم المتحدة للنطوير الصناعي unido .

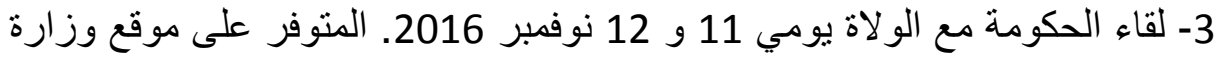
الداخلية الساعة:19.00. 4- المادة 1/43 من دستور 2016 الصادر بموجب القانون 16-16-016 المؤرخ في

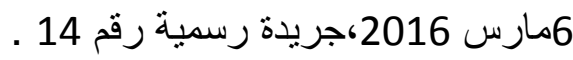
5- المادة 43/ف 3 من الدستور.

6- قد يكون الاستثمار في العقار ات أو الأوراق المالية أو المشروعات التهات التجارية.

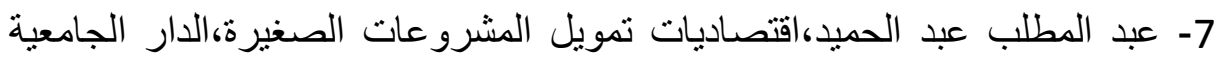
للنشر ،مصر ، 2009، ص ص 45 و ما بعدها. 8- انظر عبد المولى طشطوش ،المشروعات الصغيرة و دور ها في التنمية،دار الكامل

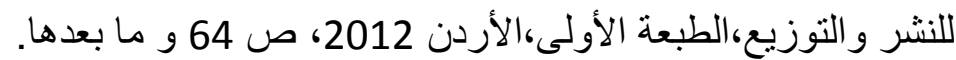
9 -voir : Khaled BOUABDALLAH, et Abdellah ZOUACHE : « Entrepreneuriat et développement économique », in : 
les cahiers du Cread n 73/2005. P17

10 -ibid ,p18 et s

11- مجادي رضوان ،سياسات الاستثمار المحلي على ضوء الأزمة الاقتصادية الادية

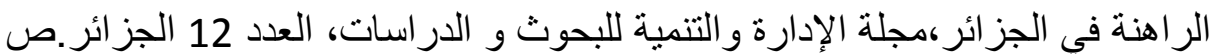
60 و وما بعدها. 12 - القانون (11-10 )المؤرخ في 22 جوان 2011 المتعلق بالبلدية( جريدة رسمية

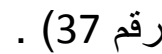
13- حسب نص المواد : 111 و 112 و 118/ف2 و 122 من قانون البلدية. 14- المادة 117/ف1 من نفس القانون. 15- القانون رقم(17-02 )المؤرخ في 10 يناير 2017 يتضمن القانون التوجيهي

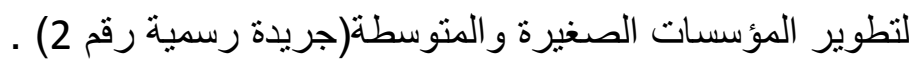
16- حسب نص المادة 122 من قانون البلدية .

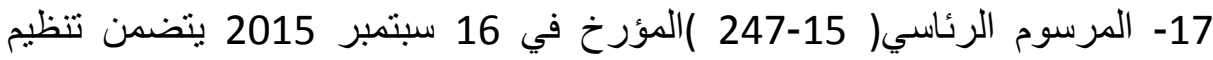
الصفقات العمومية و تفويضات المرفق العام. 18- المرسوم التنفيذي( 18-199 )المؤرخ في 2غنت فئ 2018 يتعلق بتفويض المرفق العام( جريدة رسمية رقم 48). 19- الأمر( 03-03 ) المتضمن قانون رسمة المنافسة المعدل و المتمم . 20- حسب نص المادة 132 من قانون البلدية. 21- اللامركزية الاقتصادية تعني أن تعود صلاحية تسيير المشاريع الفادية الاقتصادية للأقاليم وليس للمركز وحده. 22- القانون( 12-07 )المؤرخ في 21 فبراير 2012 يتعلق بالولاية(جريدة رسمية

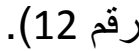

$$
\text { 23- حسب نص المادة } 84 \text { من قانون الو لاية. }
$$

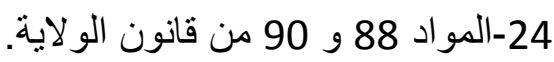
25- المادة 102 وما بعدها من قانون الولاية . 26- بن حدة باديس،الاتجاهات الحديثة لتطوير الإدارة المحلية في الوطن العربي-

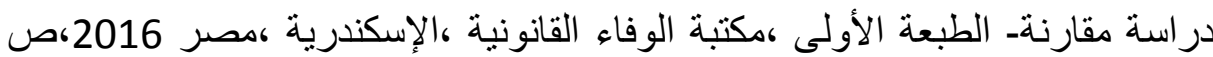
.194

27- بن حدة باديس،المرجع نفسه،ص .280 28- هثام مصطفى محمد سالم الجمل،الثراكة بين القطاعين العام والخاص كأداة

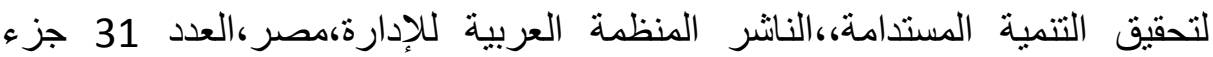
.4/2016.ص 1678

أو على موقع: https://search.mandumah.com 29-تقنية ليبر الية لارتباط ظهور ها بالنظام الليبر الي و تطوره خاصة في فرنسا. 30- مثلا قانون تسيير الخدمة العمومية للمياه و التطهير في 2005(القانون 0512)،لمزيد منن التفصيل راجع: فوناس سهيلة،تفويض المرفق العام في القانون 
الجزائري،دكتوراه في القانون،كلية الحقوق -جامعة مولود معمري-تيزي

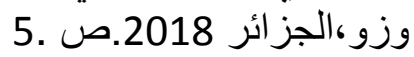

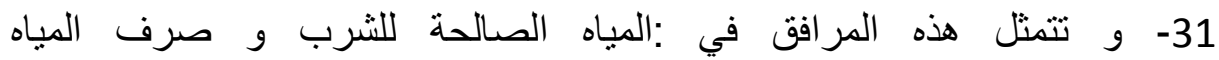

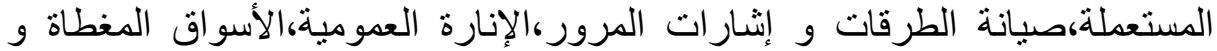

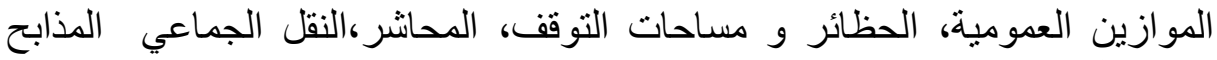

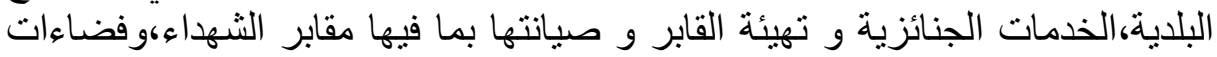

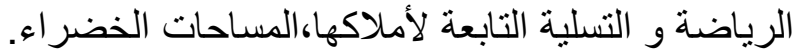
32- نادية ضريفي،تسيير المرفق العام و التحو لات الجديدة،دار بلقيس للنشر ،الجزائر

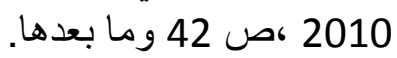
33- وليد حيدر جابر،التفويض في إدارة و استثمار المرافق العامة-دراسة مقارنةـ

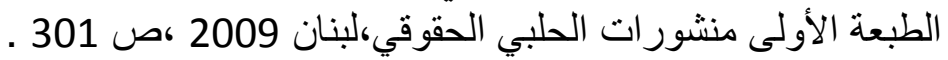

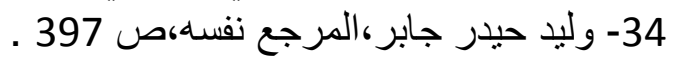

35- N .Maatala,M.Ben Abdallah,P.Lebailly,Les partenariats public-privé :fondement théorique et analyse économique ,revue Marocaine de sciences d'Agronomie et vétérinaire, Maroc,2017/5.p197 et s.

36- ibid. et voir aussi :F .Marty,A.Voisin,S .Trosa :Les partenariats public-privé ;édition la découverte ,Paris 2006 .p 03 et S.

37-- محمد عبد الخالق محمد الزعبي،عقود الثراكة بين القطاعين العام و الخاص

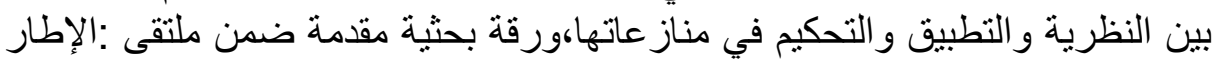

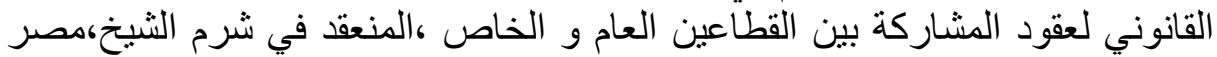

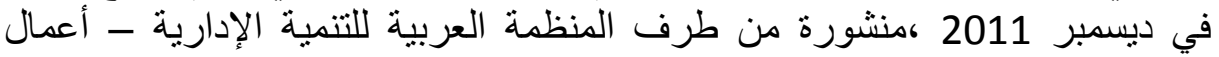

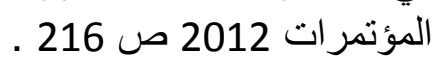

38- يتضح ذلك من خلال إبرام ميثاق الثراكة في 2012/12/23 بين التين الحكومة و منظمات أرباب العمل و الاتحاد العام للعمال الجزائريين،غئرانير أنها تبقى وثنيقة غير

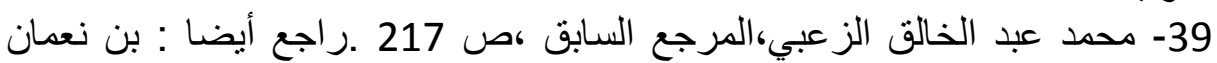

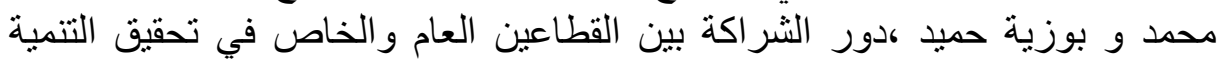

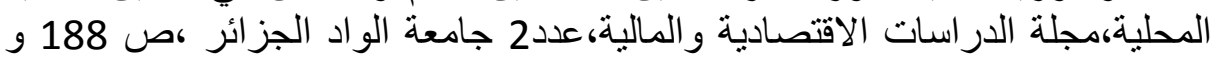

